\title{
A Lateralized Deficit in Morphine Antinociception after Unilateral Inactivation of the Central Amygdala
}

\author{
Barton H. Manning \\ Department of Neurology, University of California, San Francisco, San Francisco, California 94143-0114
}

The amygdala is a forebrain region that is receiving increasing attention as a modulator of pain sensation. The amygdala contributes to antinociception elicited by both psychological factors (e.g., fear) and exogenous opioid agonists. Unlike the midbrain periaqueductal gray matter (PAG) or rostral ventromedial medulla, the amygdala is a pain-modulating region that has clear bilateral representation in the brain, making it possible to determine whether pain-modulating effects of this region are lateralized with respect to the peripheral origin of noxious stimulation. Unilateral inactivation of the central nucleus of the amygdala (Ce) plus adjacent portions of the basolateral amygdaloid complex (with either the excitotoxin NMDA or the GABA agonist muscimol) reduced the ability of morphine to suppress prolonged, formalin-induced pain derived from the hindpaw ipsilateral, but not contralateral, to the inactivated region. This effect was evident regardless of the nociceptive scoring method used (weighted scores or flinch-frequency method) and was not accompanied by a concurrent reduction in morphine-induced hyperlocomotion. Unilateral lesions restricted to the basolateral amygdaloid complex (i.e., not including the $\mathrm{Ce}$ ) did not reduce the ability of morphine to suppress formalin-induced pain derived from either hindpaw. The results constitute the first report of a lateralized deficit in opioid antinociception after unilateral inactivation of a specific brain area and show the first clear neuroanatomical dissociation between antinociceptive and motor effects of systemically administered morphine in the rat. The amygdala appears to modulate nociceptive signals entering the ipsilateral spinal dorsal horn, probably through monosynaptic connections with ipsilateral portions of the PAG.

Key words: pain; antinociception; analgesia; morphine; opioid; formalin test; amygdala; central nucleus; lesion; NMDA; muscimol; inactivation; fear; defense reaction
Pain-modulating circuits in the brainstem and spinal cord have been identified and well characterized (Fields et al., 1991; Proudfit and Yeomans, 1995). These circuits partly comprise neurons originating from the midbrain periaqueductal gray matter (PAG) and rostral ventromedial medulla (RVM) (Fields et al., 1991). The RVM sends axons through the dorsolateral funiculus (DLF) to the dorsal horn of the spinal cord (Basbaum and Fields, 1979; Abols and Basbaum, 1981; Fields et al., 1995), where it exerts bidirectional control over transmission of nociceptive signals.

The amygdala is a forebrain structure that is well positioned to influence pain-modulating circuits in the brainstem and spinal cord. The amygdala has direct, reciprocal connections with the PAG (Rizvi et al., 1991). Neurons originating from the central nucleus of the amygdala $(\mathrm{Ce})$ strongly contribute to the antinociceptive effect of systemically administered morphine (Manning and Mayer, 1995a,b), and injection of $\mu$-opioid agonists or other compounds into several different amygdaloid nuclei results in antinociception (Rodgers, 1977; Kalivas et al., 1982; Al-Rodhan et al., 1990; Klamt and Prado, 1991; Helmstetter et al., 1993, 1995; Oliveira and Prado, 1994; Pavlovic and Bodnar, 1998) that is mediated, in part, by neurons in the PAG (Pavlovic et al., 1996; Helmstetter et al., 1998). The role of the amygdala in antinoci-

\footnotetext{
Received July 14, 1998; accepted Aug. 19, 1998.

This work was supported by the Medical Research Council of Canada and United States Public Health Service Grants NS 24009 and DA 01949. Thanks are extended to Leslie P. Keniston and Irit Levit for technical assistance and to Dr. Denes Budai for assistance in preparing Fig. 16. I also thank Drs. David J. Mayer and Howard L. Fields for their generous support of this research.

Correspondence should be addressed to Barton H. Manning, Department of Neurology, University of California, San Francisco, 513 Parnassus Avenue, S-784, San Francisco, CA 94143-0114.

Copyright (C) 1998 Society for Neuroscience $\quad 0270-6474 / 98 / 189453-18 \$ 05.00 / 0$
}

ception is consistent with its role in the generation of emotions (Aggleton, 1993; Gallagher and Chiba, 1996) and defense reactions (Graeff, 1994), and amygdaloid circuitry contributing to morphine antinociception probably overlaps with circuitry mediating the "defensive" antinociception that accompanies fear (Helmstetter et al., 1995; Manning and Mayer, 1995a,b).

The somatotopic and viscerotopic organization of endogenous pain control circuitry is still not understood completely. Nevertheless, neuroanatomical evidence suggests that pain-modulating neurons in the brain exert their influence primarily on nociceptive signals entering the ipsilateral spinal dorsal horn. Tracing studies indicate that projections from the $\mathrm{Ce}$ to the ventrolateral PAG are primarily ipsilateral in nature (Hopkins and Holstege, 1978; Beitz, 1982; Rizvi et al., 1991; Shaikh et al., 1994). Similarly, projections from the PAG to the RVM target primarily ipsilateral portions of this region (Abols and Basbaum, 1981; Williams and Beitz, 1989; Van Bockstaele et al., 1991), and RVM neurons project primarily in the ipsilateral DLF to nociceptive neurons in dorsal horn laminae I, II, and IV-VI (Leichnetz et al., 1978; Basbaum and Fields, 1979; Watkins et al., 1980; Cho and Basbaum, 1989; Fields et al., 1995).

Although the apparent ipsilateral topography of descending pain control circuitry is supported by electrophysiological evidence (Fields et al., 1977), this organizational principle has not been demonstrated clearly with regard to behavioral indices of antinociception. The PAG and RVM are both midline structures, making it difficult to unilaterally inactivate these areas and test for selective impairment of antinociception on one side of the body. The DLF, by contrast, has clear bilateral representation in the spinal cord, but the effects of unilateral DLF lesions on behavioral antinociception have not been investigated systematically. 
The clear bilateral representation of the amygdala in the forebrain makes it possible to unilaterally inactivate neurons originating from the $\mathrm{Ce}$. The purpose of the present experiments was to determine whether unilateral inactivation of a portion of amygdala that includes the Ce results in a lateralized deficit in morphine antinociception. It was hypothesized that this procedure would reduce the ability of systemic morphine to suppress formalin-induced nociception derived from the hindpaw ipsilateral, but not contralateral, to the inactivated region. In this way, parallels between the apparent neuroanatomical organization of endogenous pain control circuitry and its functional organization in terms of behavioral antinociception could be elucidated.

\section{EXPERIMENT 1}

The purpose of this experiment was to test the ability of a single dose of morphine sulfate $(6 \mathrm{mg} / \mathrm{kg})$ to suppress formalin-induced nociceptive behaviors in rats with unilateral, excitotoxin-induced lesions of a portion of amygdala that includes the Ce (hereafter referred to as unilateral Ce lesions). The $\mathrm{Ce}$ was chosen as the focus of this experiment because our previous mapping studies using bilateral lesions suggested that the $\mathrm{Ce}$ is the major amygdaloid contributor to the antinociceptive effect of systemic morphine (Manning and Mayer, 1995a,b). In some rats, formalin was administered to the hindpaw ipsilateral to the Ce lesion. In other rats, formalin was administered to the hindpaw contralateral to the Ce lesion. Rats with unilateral Ce sham lesions were prepared and tested as controls.

\section{Materials and methods}

Subjects. Experimentally naive, male Sprague Dawley rats (Hilltop, Scottdale, PA) weighing 300-325 gm at the time of surgery were used. Animals were housed individually in cages on a $12 \mathrm{hr}$ light/dark schedule (lights on at 7:00 A.M.) with food and water available ad libitum. All experimental procedures were approved by the Institutional Animal Care and Use Committee.

Experimental design. Each rat in Experiment 1 underwent two formalin test sessions separated by $7 \mathrm{~d}$. For one of the sessions the rat received a subcutaneous injection of morphine sulfate $(6 \mathrm{mg} / \mathrm{kg}) 5 \mathrm{~min}$ before the formalin injection. For the other session the rat received a subcutaneous injection of physiological saline 5 min before formalin injection. Rats were surgically prepared for this experiment in the following manner: (1) rats with unilateral $\mathrm{Ce}$ lesions, and (2) rats with unilateral $\mathrm{Ce}$ sham lesions. Rats in each of these categories were subdivided further based on the hindpaw that would receive formalin $(1.0 \%, 50 \mu \mathrm{l})$ during the test session in which morphine was administered. Thus, some rats received formalin in the hindpaw ipsilateral to their unilateral $\mathrm{Ce}$ treatment (lesion or sham lesion) after morphine administration, whereas others received formalin in the hindpaw contralateral to their unilateral $\mathrm{Ce}$ treatment after morphine administration. For the systemic saline test session, formalin was administered to the hindpaw that was not used during the morphine test session. By this arrangement, some unilateral Ce-treated rats were tested with systemic morphine plus ipsilateral formalin and systemic saline plus contralateral formalin, whereas other unilateral Ce-treated rats received systemic morphine plus contralateral formalin and systemic saline plus ipsilateral formalin. The order of systemic drug administration (and consequently the order of hindpaw formalin injection) and the side of the unilateral Ce treatment (left or right hemisphere) were counterbalanced within each group.

Rats in this experiment were tested with a dose of $6 \mathrm{mg} / \mathrm{kg}$ morphine sulfate. This dose was chosen because in normal rats it produces powerful, yet submaximal, suppression of nociceptive behaviors associated with an injection of $1.0 \%$ formalin. It was hoped that by using this dose, quantitative differences between various experimental groups would be readily detectable. A concentration of $1.0 \%$ formalin was used for hindpaw injection because it produces vigorous and easily quantifiable pain responses in rats. These responses are significantly lower in magnitude and frequency than those produced by higher doses of formalin (Coderre et al., 1993; Abbott et al., 1995), thereby making detection of hyperalgesia possible (Tjølsen et al., 1992).
Surgery. Rats were anesthetized with sodium pentobarbital $(48 \mathrm{mg} / \mathrm{kg}$, i.p.). Using standard stereotaxic equipment, a stainless steel injection cannula (30 gauge) was lowered unilaterally into the Ce according to the atlas of Paxinos and Watson (1986) [Ce coordinates: anteroposterior (AP), $-2.5 \mathrm{~mm}$ posterior to bregma; lateral, $\pm 4.4 \mathrm{~mm}$; and ventral, -8.2 $\mathrm{mm}$ below the lambda/bregma plane). The cannula was connected, via polyethylene tubing (PE-10) to an infusion pump (Harvard Apparatus, South Natick, MA). After 5 min, either NMDA $(0.30 \mathrm{M}$ in $0.1 \mathrm{M} \mathrm{PBS}, \mathrm{pH}$ 7.4; Sigma, St. Louis, MO) or vehicle alone was infused slowly into the target site over a $5 \mathrm{~min}$ period such that the final volume of injection was $150 \mathrm{nl}$. The cannula was left in place an additional $5 \mathrm{~min}$ to allow sufficient time for absorption and to prevent reflux. The cannula was removed, and the scalp wound was closed with wound clips. Each rat received an injection of diazepam ( $1 \mathrm{mg}$, i.p.) and was placed on a thermal mat. Lesion rats were monitored for early signs of seizure activity until they awoke from surgery. If such activity was noted, an additional injection of diazepam (1 mg, i.p.) was administered. Each rat was allowed to recover from the surgical procedure for $7 \mathrm{~d}$ before the first nociceptive testing began.

Nociceptive testing. Ambient temperature of the test room was maintained at $24 \pm 0.5^{\circ} \mathrm{C}$ at all times. After $3 \mathrm{~d}$ of acclimation to the testing equipment and personnel $(30 \mathrm{~min} / \mathrm{d})$, each rat received two formalin injections. The injections were separated by $7 \mathrm{~d}$, and a different hindpaw was used on each occasion. Nociceptive scoring was performed with the rat free to move around in a Plexiglas observation box. The box measured $34 \times 34 \times 34 \mathrm{~cm}$, and a mirror below the floor angled at $45^{\circ}$ allowed for an unobstructed view of the rat's paws. Each test session began with the subcutaneous injection of either morphine sulfate $(6 \mathrm{mg} / \mathrm{kg})$ or physiological saline. The rat then was placed in the observation box for $5 \mathrm{~min}$ before receiving a $50 \mu \mathrm{l}$ injection of $1.0 \%$ formalin into the plantar surface of one hindpaw. Scoring of nociceptive behaviors started immediately and continued for the next $50 \mathrm{~min}$, with the rater blind as to which treatment group the subject belonged.

Two methods of scoring were used simultaneously to quantify nociception: (1) the weighted scores, or rating scale, method (Cohen et al., 1984; Coderre et al., 1993; Abbott et al., 1995), and (2) the flinchfrequency method (Ryan et al., 1985; Wheeler-Aceto and Cowan, 1991). Nociception was quantified using the rating scale method by assigning weights to the following categories of pain-related behaviors: (1) the rat walks or sits normally without favoring the injected paw (weight $=0) ;(2)$ the rat walks or sits while placing some but not full pressure on the injected paw (weight $=1$ ); $(3)$ the rat walks or sits while maintaining the paw completely elevated off the floor (weight $=2$ ); and $(4)$ the rat licks, bites, or vigorously shakes the injected paw (weight $=3$ ). A weighted average nociceptive score was obtained for each $5 \mathrm{~min}$ test interval by multiplying the number of seconds the rat spent in each category by its assigned weight, summing these products, and dividing by the total time (300 sec):

$$
\text { Nociceptive score }=\frac{\left(t_{0} \times 0\right)+\left(t_{1} \times 1\right)+\left(t_{2} \times 2\right)+\left(t_{3} \times 3\right)}{t_{0}+t_{1}+t_{2}+t_{3}} .
$$

By using this method, an ordinal scale (Coderre et al., 1993) of nociceptive scores is generated with a range of $0-3$.

The flinch-frequency method of scoring was performed by recording the total number of episodes of lifting, flinching, or shaking of the injected paw per 5 min scoring interval (Wheeler-Aceto and Cowan, 1991).

Scoring of horizontal locomotor activity. In addition to scoring of nociceptive behaviors, rats' horizontal locomotor activity levels (Segal and Kuczenski, 1992; Wise et al., 1996) were monitored throughout each formalin test session (Sawynok et al., 1995). The floor of the Plexiglas observation box was divided into quadrants, and the number of times the rat crossed over completely (all four paws) from one quadrant into an adjacent quadrant was recorded during each $5 \mathrm{~min}$ formalin test interval.

Histology. Immediately after completion of the second formalin test, rats were overdosed with sodium pentobarbital $(100 \mathrm{mg} / \mathrm{kg})$ and perfused through the heart with $0.9 \%$ saline followed by $10 \%$ formalin. The brains were removed and stored overnight in a $10 \%$ formalin $/ 10 \%$ sucrose solution. The following morning the brains were quickly frozen and sliced at $-25^{\circ} \mathrm{C}$. Coronal sections $(20 \mu \mathrm{m}$ thick) were taken starting at the anterior commissure and ending at the caudal limit of the amygdala, with every fifth section mounted on a microscope slide. The sections were stained with cresyl violet and coverslipped. Brains infused with NMDA were inspected with a light microscope for gliosis and neuronal 
cell loss compared with brains inf used with vehicle (Hastings et al., 1985; Winn et al., 1990). In addition, the amygdala contralateral to the side of NMDA injection was inspected for signs of neuronal cell loss or gliosis.

For each unilateral Ce lesion group, rat subjects were included for statistical analysis if the Ce was damaged by at least $80 \%$ (including its medial and lateral subdivisions; Manning and Mayer, 1995a,b). Lesion mapping was performed blind to the behavioral results.

Statistical analyses. Rating scale and locomotor activity data collected from Ce-treated rats (lesion and sham lesion) were analyzed in separate three-way ANOVAs (lesion $\times$ systemic drug $\times$ time), with systemic drug treatment and time analyzed as repeated measures. Multiple pairwise comparisons were made using Tukey's honestly significant difference (HSD) tests.

Because of the large number of groups (cells) in each experiment displaying mean flinch scores of zero, flinch scores were analyzed nonparametrically. Independent groups were compared using the MannWhitney $U$ test. Related groups were compared using the Wilcoxon signed-rank test.

\section{Results}

\section{Histology: unilateral Ce-treated rats}

Ipsilateral formalin and systemic morphine. The extent of neuronal cell loss corresponding to unilateral Ce lesion rats treated with morphine plus ipsilateral formalin $(n=9)$ is illustrated in Figure 1 (for a photomicrograph of typical NMDA-induced lesions of the Ce, see Manning and Mayer, 1995a,b). Note that four rats had lesions of the left amygdala, whereas another five rats had lesions of the right amygdala. The dark shading in Figure 1 indicates a damaged area common to all rats with Ce lesions in the right or left hemisphere. In eight of the nine Ce lesion cases, there was substantial neuronal cell loss at all anteroposterior levels of the Ce. In the remaining case, $>95 \%$ of the Ce suffered substantial neuronal cell loss. In all nine cases, neuronal damage extended dorsally into portions of overlying globus pallidus and caudateputamen. Furthermore, in all nine cases damage extended into the basolateral nucleus (BL) and portions of the lateral nucleus, in addition to varying amounts of damage to the intra-amygdaloid division of the bed nucleus of the stria terminalis. The medial nucleus was spared for the most part in five cases, but the other four cases had extensive, but incomplete, damage to this nucleus.

Contralateral formalin and systemic morphine. The extent of neuronal cell loss corresponding to unilateral $\mathrm{Ce}$ lesion rats treated with morphine plus contralateral formalin $(n=9)$ is illustrated in Figure 2. Note that four rats had lesions of the left amygdala, whereas another five rats had lesions of the right amygdala. The pattern of neuronal cell loss was similar to $\mathrm{Ce}$ lesion rats treated with morphine plus ipsilateral formalin (above). The dark shading in Figure 2 indicates a damaged area common to all rats with Ce lesions in the right or left hemisphere. In eight of the nine Ce lesion cases, there was substantial neuronal cell loss at all anteroposterior levels of the $\mathrm{Ce}$. In the remaining case, $>95 \%$ of the Ce suffered substantial neuronal cell loss. In all nine cases, neuronal damage extended dorsally into portions of overlying globus pallidus and caudate-putamen. Furthermore, in eight of nine cases damage extended into the BL and portions of the lateral nucleus, in addition to varying amounts of damage to the intra-amygdaloid division of the bed nucleus of the stria terminalis. The medial nucleus was spared for the most part in five cases, but the other four cases had extensive, but incomplete, damage to this nucleus.

\section{Nociceptive and locomotor activity scores: unilateral Ce-treated rats}

Ipsilateral formalin and systemic morphine. Figure 3 shows rating scale (Fig. 3A), flinch (Fig. 3B), and horizontal locomotor activity

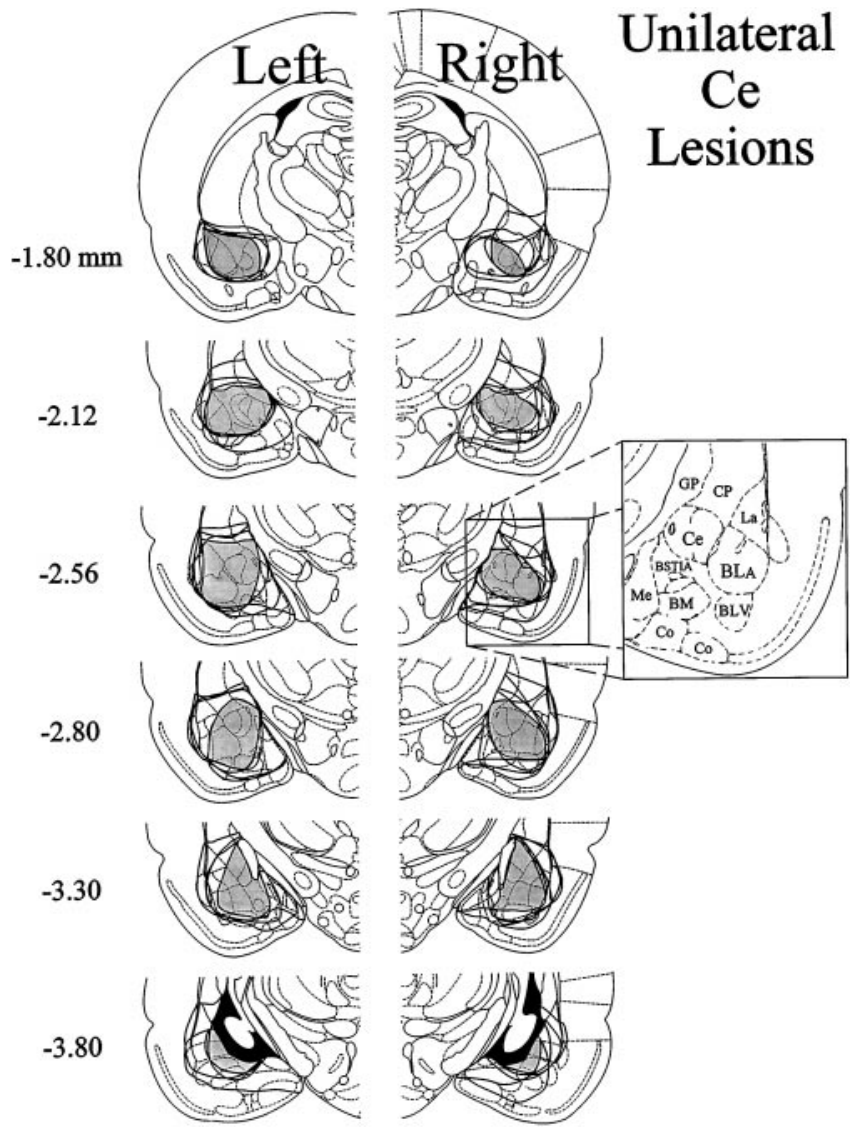

Figure 1. Histological results of Experiment 1: unilateral Ce lesions, morphine and ipsilateral formalin. Representations of six coronal sections through the rat forebrain are shown in sequence from anterior to posterior. The numbers in the left margin indicate millimeters posterior to bregma. The closed curves illustrate the borders of lesions that included the $\mathrm{Ce}(n=9)$ in each hemisphere, as determined by the extent of neuronal cell loss and gliosis. Note that four rats had lesions placed in the left cerebral hemisphere, whereas the other five had lesions placed in the right cerebral hemisphere. The lesion area common to all rats in each hemisphere is shown as dark shading. Note that $>95 \%$ of the Ce was damaged unilaterally in all nine rats. Adapted from Paxinos and Watson (1986). Amygdaloid areas: $C e$, central nucleus; $B L A$, basolateral nucleus, anterior; $B L V$, basolateral nucleus, ventral; $B S T I A$, bed nucleus of the stria terminalis, intra-amygdaloid division; $M e$, medial nucleus; $B M$, basomedial nucleus; $\mathrm{Co}$, cortical amygdaloid nuclei. Extra-amygdaloid areas: $G P$, globus pallidus; $C P$, caudate-putamen.

(Fig. 3C) scores of the first group of Ce-treated rats in Experiment 1 . These rats received a subcutaneous injection of morphine followed $5 \mathrm{~min}$ later by injection of formalin into the hindpaw ipsilateral to their Ce treatment (either NMDA or vehicle). Rats in this group were tested on another occasion with a subcutaneous injection of saline followed $5 \mathrm{~min}$ later by injection of formalin into the hindpaw contralateral to their Ce treatment.

An ANOVA performed on the rating scale scores revealed a significant interaction among lesion, systemic drug, and time in unilateral Ce-treated rats $\left(F_{(9,135)}=2.09 ; p<0.05\right)$. Tukey's HSD tests detected no significant differences in baseline (i.e., systemic saline) scores between $\mathrm{Ce}$ lesion and $\mathrm{Ce}$ sham lesion rats (Fig. $3 A ; p>0.05$ at all time points). Morphine administered 5 min before formalin produced significantly lower rating scale scores, compared with saline, in Ce sham lesion rats during the second (10-50 min after formalin injection) phase of the formalin test (Fig. $3 A$; Tukey's HSD tests; $p<0.01$ at all time points). 


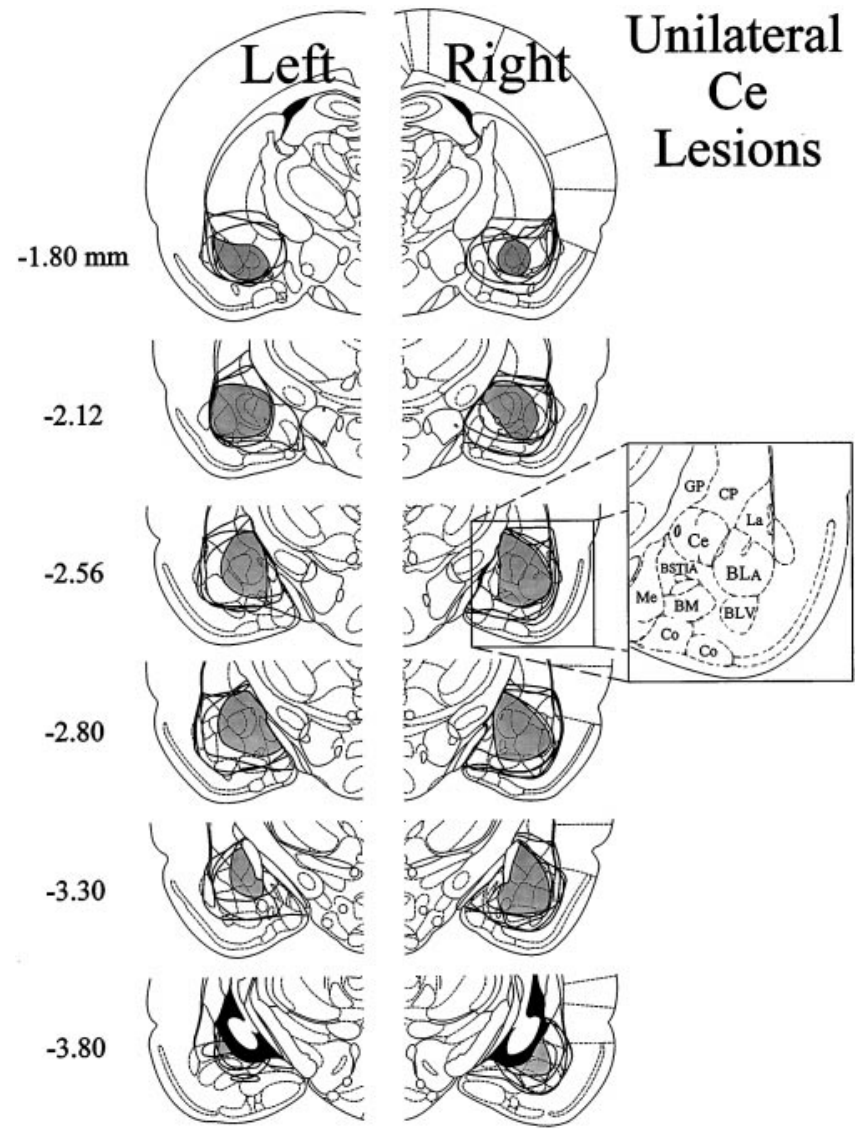

Figure 2. Histological results of Experiment 1: unilateral Ce lesions, morphine and contralateral formalin. Representations of six coronal sections through the rat forebrain are shown in sequence from anterior to posterior. The numbers in the left margin indicate millimeters posterior to bregma. The closed curves illustrate the borders of lesions that included the $\mathrm{Ce}(n=9)$ in each hemisphere, as determined by the extent of neuronal cell loss and gliosis. Note that four rats had lesions placed in the left cerebral hemisphere, whereas the other five had lesions placed in the right cerebral hemisphere. The lesion area common to all rats in each hemisphere is shown as dark shading. Note that $>95 \%$ of the Ce was damaged unilaterally in all nine rats. Adapted from Paxinos and Watson (1986). Amygdaloid areas: $C e$, central nucleus; $B L A$, basolateral nucleus, anterior; $B L V$, basolateral nucleus, ventral; $B S T I A$, bed nucleus of the stria terminalis, intra-amygdaloid division; $M e$, medial nucleus; $B M$, basomedial nucleus; $\mathrm{Co}$, cortical amygdaloid nuclei. Extra-amygdaloid areas: $G P$, globus pallidus; $C P$, caudate-putamen.

Compared with $\mathrm{Ce}$ sham lesion rats, however, morphine treatment in Ce lesion rats yielded significantly higher rating scale scores during the time interval 20-50 min after formalin injection (Fig. 3A; Tukey's HSD tests, $p<0.05$ in all cases). Furthermore, morphine did not produce significantly lower scores than saline in Ce lesion rats during the time interval 20-45 min after formalin injection (Fig. 3A; Tukey's HSD tests, $p>0.05$ ).

Flinch scores obtained from the same group of Ce-treated rats are shown in Figure $3 B$. The analysis of flinch scores yielded a similar pattern of results as that obtained with the rating scale method (Fig. 3, compare $A, B$ ).

Horizontal locomotor activity scores obtained from the same group of Ce-treated rats are shown in Figure 3C. An ANOVA performed on these scores revealed a significant interaction between systemic drug treatment and time in unilateral Ce-treated rats $\left(F_{(9,135)}=335.514 ; p<0.0001\right)$. Further analysis of the interaction showed that morphine produced significantly higher horizontal locomotor activity scores than saline in Ce-treated rats during the intervals 5-25 and 45-50 min after formalin injection (Fig. 3C; Tukey's HSD tests, $p<0.05$ ). There was, however, no significant main effect of lesion $\left(F_{(1,15)}=0.47722 ; p>0.05\right)$, nor was there a significant interaction between lesion and systemic drug treatment $\left(F_{(1,15)}=0.00024 ; p>0.05\right)$, indicating that horizontal locomotor activity scores were not significantly different overall between unilateral $\mathrm{Ce}$ lesion and unilateral $\mathrm{Ce}$ sham lesion rats.

Contralateral formalin and systemic morphine. Figure 4 shows rating scale (Fig. 4A), flinch (Fig. 4B), and horizontal locomotor activity (Fig. $4 C$ ) scores of the second group of Ce-treated rats in Experiment 1. These rats received a subcutaneous injection of morphine followed $5 \mathrm{~min}$ later by injection of formalin into the hindpaw contralateral to their Ce treatment (either NMDA or vehicle). Rats in this group were tested on another occasion with a subcutaneous injection of saline followed 5 min later by injection of formalin into the hindpaw ipsilateral to their Ce treatment.

An ANOVA performed on the rating scale scores revealed a significant main effect of systemic drug treatment $\left(F_{(1,15)}=\right.$ 148.275; $p<0.0001)$ but neither a significant interaction between lesion and systemic drug treatment $\left(F_{(1,15)}=0.3737 ; p>0.05\right)$ nor a significant main effect of lesion $\left(F_{(1,15)}=0.95919 ; p>0.05\right)$. The data indicate that morphine produced significantly lower rating scale scores than saline (i.e., significant antinociception was produced) in both unilateral $\mathrm{Ce}$ lesion and unilateral $\mathrm{Ce}$ sham lesion rats (Fig. 4A). The data further indicate that, in contrast to unilateral Ce lesion rats treated with ipsilateral formalin (Fig. 3A), the effects of morphine in unilateral Ce lesion rats treated with contralateral formalin were not significantly different from those in unilateral $\mathrm{Ce}$ sham lesion rats treated with contralateral formalin.

Flinch scores obtained from the same group of Ce-treated rats are shown in Figure $4 B$. The analysis of flinch scores yielded a similar pattern of results as that obtained with the rating scale method (Fig. 4, compare $A, B$ ), with one exception: unilateral Ce lesion rats treated with systemic saline showed slightly lower flinch scores than unilateral $\mathrm{Ce}$ sham lesion rats treated with systemic saline at several time points (Fig. 4B; Mann-Whitney $U$ test, $p<0.05)$.

Horizontal locomotor activity scores obtained from the same group of Ce-treated rats are shown in Figure $4 C$. An ANOVA performed on these scores revealed a significant main effect of systemic drug treatment $\left(F_{(1,15)}=7.5988 ; p<0.05\right)$. Neither a significant interaction between lesion and systemic drug treatment $\left(F_{(1,15)}=0.19774 ; p>0.05\right)$ nor a significant main effect of lesion $\left(F_{(1,15)}=0.7265 ; p>0.05\right)$ was detected. The data indicate that morphine produced significantly higher horizontal locomotor activity scores than saline in both unilateral Ce lesion and unilateral Ce sham lesion rats (Fig. 4C). The data further indicate that horizontal locomotor activity scores were not significantly different overall between unilateral $\mathrm{Ce}$ lesion and unilateral $\mathrm{Ce}$ sham lesion rats.

Further consideration of saline control data presented above. In Experiment 1 (Figs. 3, 4), unilateral Ce lesions strongly reduced the ability of morphine to suppress formalin-induced nociception derived from the hindpaw ipsilateral, but not contralateral, to the lesion. In Experiment 1, each rat received two formalin test sessions, with morphine administered before formalin in one session and saline administered before formalin in the other session. A different hindpaw was used for each formalin test, because formalin produces a certain amount tissue damage and 

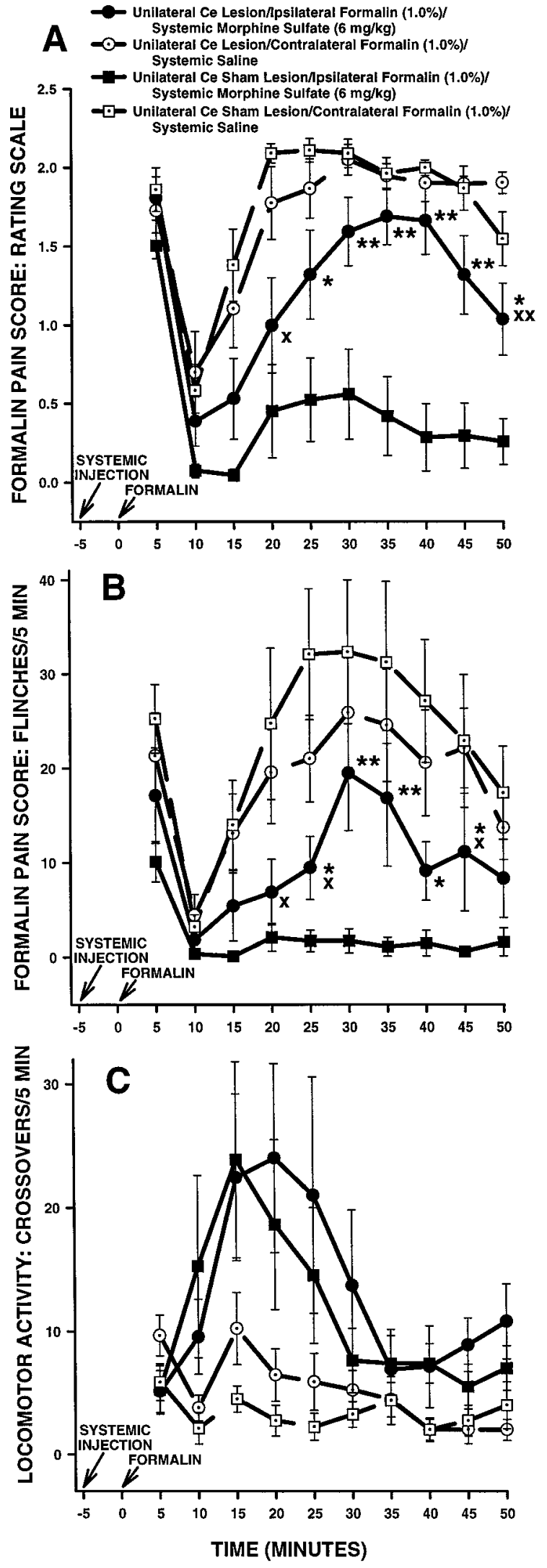

Figure 3. Average nociceptive and horizontal locomotor activity scores of unilateral $\mathrm{Ce}$-treated rats in Experiment 1: unilateral $\mathrm{Ce}$ lesions, morphine and ipsilateral formalin. Error bars indicate SEM. In this experiment, unilateral $\mathrm{Ce}$ lesion rats treated with morphine received a formalin injection into the hindpaw ipsilateral to their Ce lesion. Rating edema in the injected paw, even at relatively low concentrations (Rosland et al., 1990). Because of this constraint, baseline (i.e., systemic saline) nociceptive scores were not collected from the same paw that received formalin after morphine administration. Because a unilateral Ce lesion might have resulted in ipsilateral hyperalgesia independent of a disruption in antinociceptive mechanisms, it is important to control for this possibility.

As is turns out, baseline (i.e., systemic saline) data collected from the first group of unilateral Ce lesion rats (above, Fig. 3) can serve as a control for morphine data collected from the second group of unilateral Ce lesion rats (Fig. 4). Similarly, baseline (i.e., systemic saline) data collected from the second group of unilateral Ce lesion rats (above, Fig. 4) can serve as a control for morphine data obtained from the first group of unilateral $\mathrm{Ce}$ lesion rats (Fig. 3). To illustrate, consider the baseline data collected from the second group of rats with unilateral Ce lesions. For rats in this group, subcutaneous saline treatment preceded injection of formalin into the hindpaw ipsilateral to the Ce lesion, whereas subcutaneous morphine treatment preceded injection of formalin into the hindpaw contralateral to the Ce lesion. As a result, the baseline data collected from this group of Ce lesion rats can serve as a control for the morphine data collected from the first group of $\mathrm{Ce}$ lesion rats, because both sets of data were collected from the paw ipsilateral to the Ce lesion. Similarly, baseline data collected from the first group of Ce lesion rats can serve as a control for morphine data collected from the second group of Ce lesion rats, because data in both of these groups were collected from the hindpaw contralateral to the Ce lesion. Figure 5 shows baseline (i.e., systemic saline) data collected from both groups of unilateral $\mathrm{Ce}$ lesion rats in Experiment 1 (previously illustrated in Figs. 3, 4, respectively). Three-factor repeated measures ANOVAs revealed no significant differences between $\mathrm{Ce}$ lesion rats and $\mathrm{Ce}$ sham lesion rats with regard to rating scale scores (Fig. $5 A$; all relevant $F$ ratios, $p>0.05$ ), flinch scores (Fig. $5 B$; all relevant $F$ ratios, $p>0.05$ ), or horizontal locomotor activity scores (Fig. $5 C$; all relevant $F$ ratios, $p>0.05$ ). The results indicate that unilateral $\mathrm{Ce}$ lesions do not result in hyperalgesia in the hindpaw ipsilateral to the lesion, thereby ruling out lesioninduced hyperalgesia as a confounding factor in the interpretation of the results of Experiment 1.

\section{EXPERIMENT 2}

The results of Experiment 1 suggest that a unilateral excitotoxininduced lesion of a portion of the amygdala that includes the $\mathrm{Ce}$

\footnotetext{
$\leftarrow$

scale nociceptive scores are shown in $A$, flinch nociceptive scores are shown in $B$, and horizontal locomotor activity scores are shown in $C$. Note the similar pattern of results obtained with the rating scale and flinchfrequency methods of nociceptive scoring. There were no significant differences in baseline (i.e., systemic saline) nociceptive or horizontal locomotor activity scores at any time point between unilateral $\mathrm{Ce}$ lesion rats and unilateral $\mathrm{Ce}$ sham lesion rats (also see Fig. 5). In unilateral $\mathrm{Ce}$ sham lesion rats, morphine sulfate $(6 \mathrm{mg} / \mathrm{kg}$, s.c. $)$ produced significant antinociception compared with saline at most time points. In unilateral Ce lesion rats, however, the ability of morphine to produce antinociception was severely impaired. This effect was dissociable from the effects of morphine on horizontal locomotor activity, because morphine-induced increases in horizontal locomotor activity were unaffected by unilateral Ce lesions $(C) . A,{ }^{*} p<0.05 ;{ }^{* *} p<0.01$, Tukey's HSD test, compared with unilateral Ce sham lesion rats treated with systemic morphine; ${ }^{X} p<$ $0.05 ;{ }^{X} p<0.01$, Tukey's HSD test, compared with unilateral Ce lesion rats treated with systemic saline. $B,{ }^{*} p<0.05$; ${ }^{*} p<0.01$, Mann-Whitney $U$ test, compared with unilateral Ce sham lesion rats treated with systemic morphine; ${ }^{X} p<0.05$, Wilcoxon signed-rank test, compared with unilateral Ce lesion rats treated with systemic saline.
} 

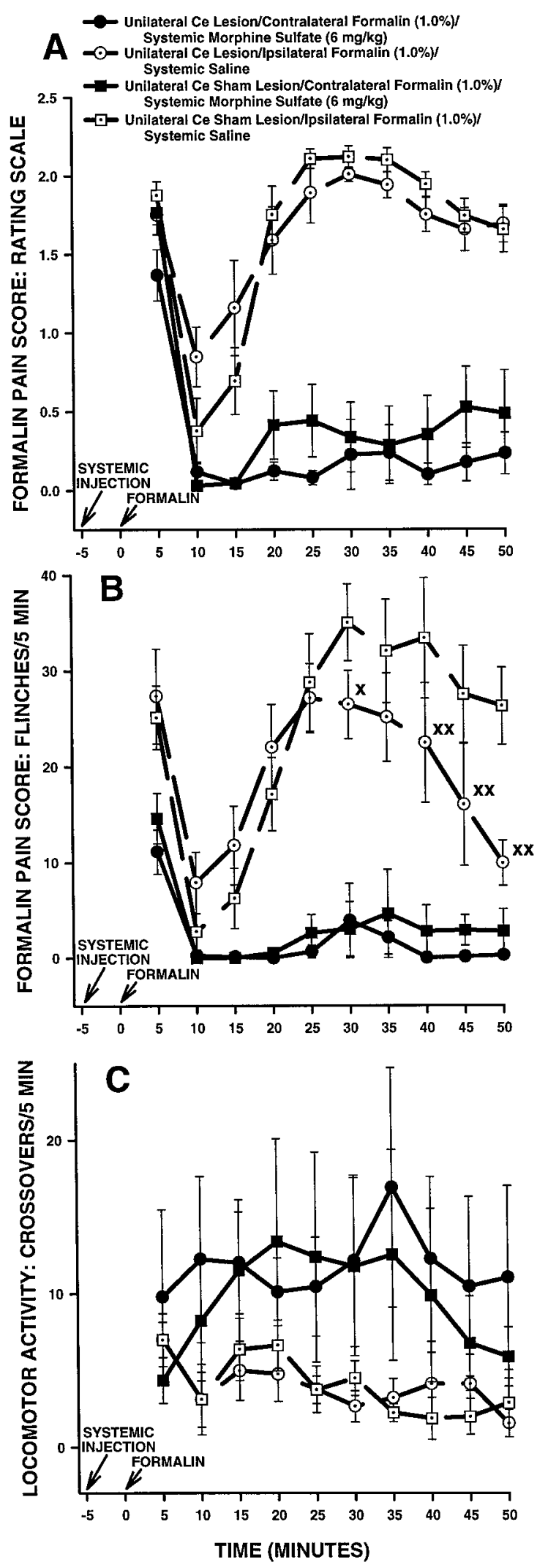

Figure 4. Average nociceptive and horizontal locomotor activity scores of unilateral Ce-treated rats in Experiment 1: unilateral Ce lesions, morphine and contralateral formalin. Error bars indicate SEM. In this experiment, unilateral $\mathrm{Ce}$ lesion rats treated with morphine received a formalin injection in the hindpaw contralateral to their Ce lesion. Rating scale nociceptive scores are shown in $A$, flinch nociceptive scores are strongly reduces the ability of morphine to suppress formalininduced nociception derived from the hindpaw ipsilateral, but not contralateral, to the lesion. These data are consistent with our previous mapping studies using bilateral lesions, which suggested that the $\mathrm{Ce}$ is the major amygdaloid contributor to the antinociceptive effect of systemic morphine (Manning and Mayer, 1995a,b). As can be seen from Figures 1 and 2, however, lesions in Experiment 1 were not confined to the $\mathrm{Ce}$. Other nuclei of the amygdala, notably the BL and lateral nucleus of the amygdala, suffered some damage (this extra-Ce damage was unavoidable because the shape of the Ce precludes lesioning a large portion of it without damaging adjacent amygdaloid areas). It is of interest, therefore, to examine the effects of a unilateral lesion restricted to the basolateral amygdaloid complex (i.e., not including the $\mathrm{Ce}$ ) on morphine antinociception. Accordingly, rats with unilateral NMDA-induced lesions or sham lesions centered on the BL were prepared. The ability of morphine to suppress formalin-induced nociception derived from the hindpaw ipsilateral or contralateral to the BL lesion was assessed.

\section{Materials and methods}

Experiment 2 was identical to Experiment 1 except that unilateral BL lesions were prepared instead of unilateral Ce lesions. Surgical groups were as follows: (1) rats with unilateral NMDA-induced lesions centered on the BL, and (2) rats with unilateral BL sham lesions. As in Experiment 1 , rats in each of these categories were subdivided further based on the hindpaw that would receive formalin $(1.0 \%, 50 \mu \mathrm{l})$ during the "morphine" test session (see Experiment 1). Stereotaxic coordinates (Paxinos and Watson, 1986) for cannula placement in the BL were AP, $-2.5 \mathrm{~mm}$; lateral, $\pm 5.2 \mathrm{~mm}$; and ventral, $-8.5 \mathrm{~mm}$.

For each BL lesion group, rat subjects were included for statistical analysis if the BL was damaged by at least $80 \%$, with no more than $20 \%$ damage to the Ce (Manning and Mayer, 1995a,b). Lesion mapping was performed blind to the behavioral results.

\section{Results \\ Histology: unilateral BL-treated rats}

Ipsilateral formalin and systemic morphine. The extent of neuronal cell loss corresponding to unilateral BL lesion rats treated with morphine plus ipsilateral formalin $(n=7)$ is illustrated in Figure 6. Note that four rats had lesions of the left BL, whereas another three rats had lesions of the right BL. The light shading in Figure 6 indicates a damaged area common to all rats with BL lesions in the right or left hemisphere. In all seven cases, there was substantial neuronal cell loss to at least $80 \%$ of the BL. In most cases this was accompanied by damage to large portions of the lateral amygdaloid nucleus and smaller portions of adjacent piriform cortex and overlying caudate-putamen. In all cases, damage extended into the lateral portion of the $\mathrm{Ce}$, although in five cases this damage was very slight. In the other two cases the Ce was damaged by $\sim 15-18 \%$.

shown in $B$, and horizontal locomotor activity scores are shown in $C$. Note the similar pattern of results obtained with the rating scale and flinchfrequency methods of nociceptive scoring. There were no significant differences in baseline (i.e., systemic saline) nociceptive or horizontal locomotor activity scores at any time point between unilateral $\mathrm{Ce}$ lesion rats and unilateral $\mathrm{Ce}$ sham lesion rats (also see Fig. 5). In unilateral $\mathrm{Ce}$ sham lesion rats, morphine sulfate $(6 \mathrm{mg} / \mathrm{kg}$, s.c.) produced significant antinociception compared with saline at most time points. Unlike lesion rats that received morphine and ipsilateral formalin (Fig. 3), unilateral $\mathrm{Ce}$ lesions did not affect morphine-induced suppression of pain derived from the contralateral hindpaw. $B,{ }^{X} p<0.05 ;{ }^{X}{ }_{p}<0.01$, Mann-Whitney $U$ test, compared with unilateral $\mathrm{Ce}$ sham lesion rats treated with systemic saline. 

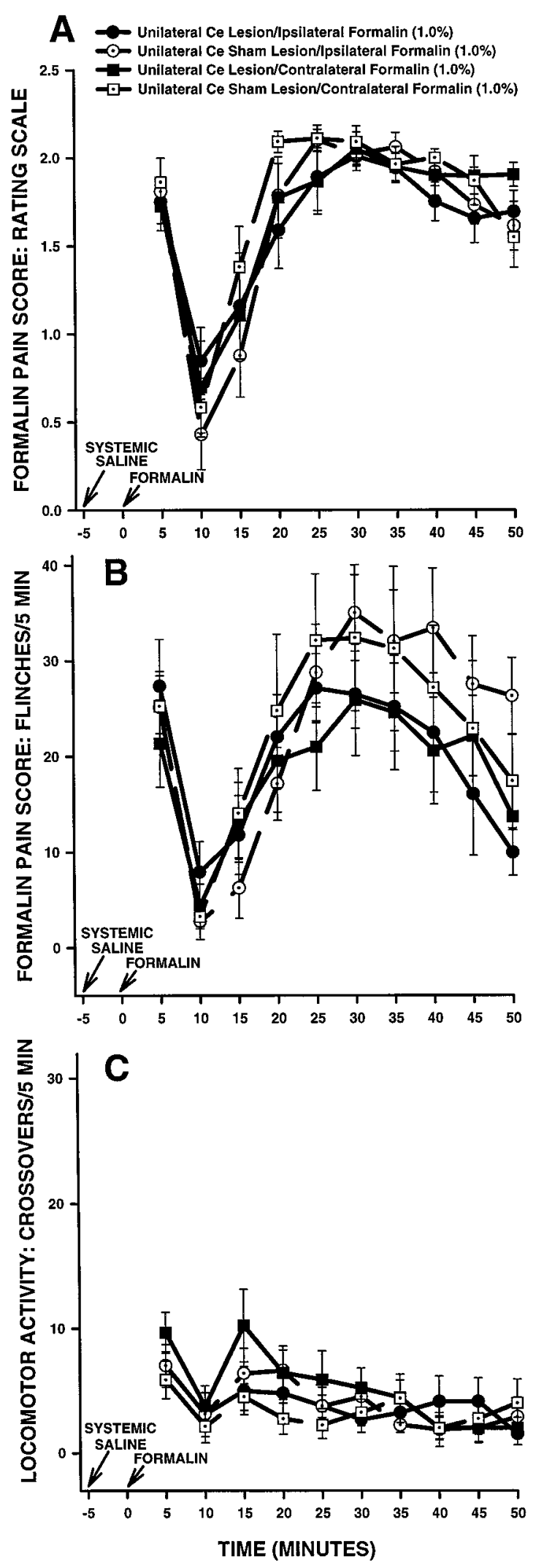

Figure 5. Average nociceptive and horizontal locomotor activity scores of unilateral $\mathrm{Ce}$ sham and unilateral Ce lesion rats treated with systemic saline in Experiment 1. Rating scale nociceptive scores are shown in $A$, flinch nociceptive scores are shown in $B$, and horizontal locomotor activity scores are shown in $C$. Error bars indicate SEM. Saline control data collected in Experiment 1 (see Figs. 3, 4) are presented in the same

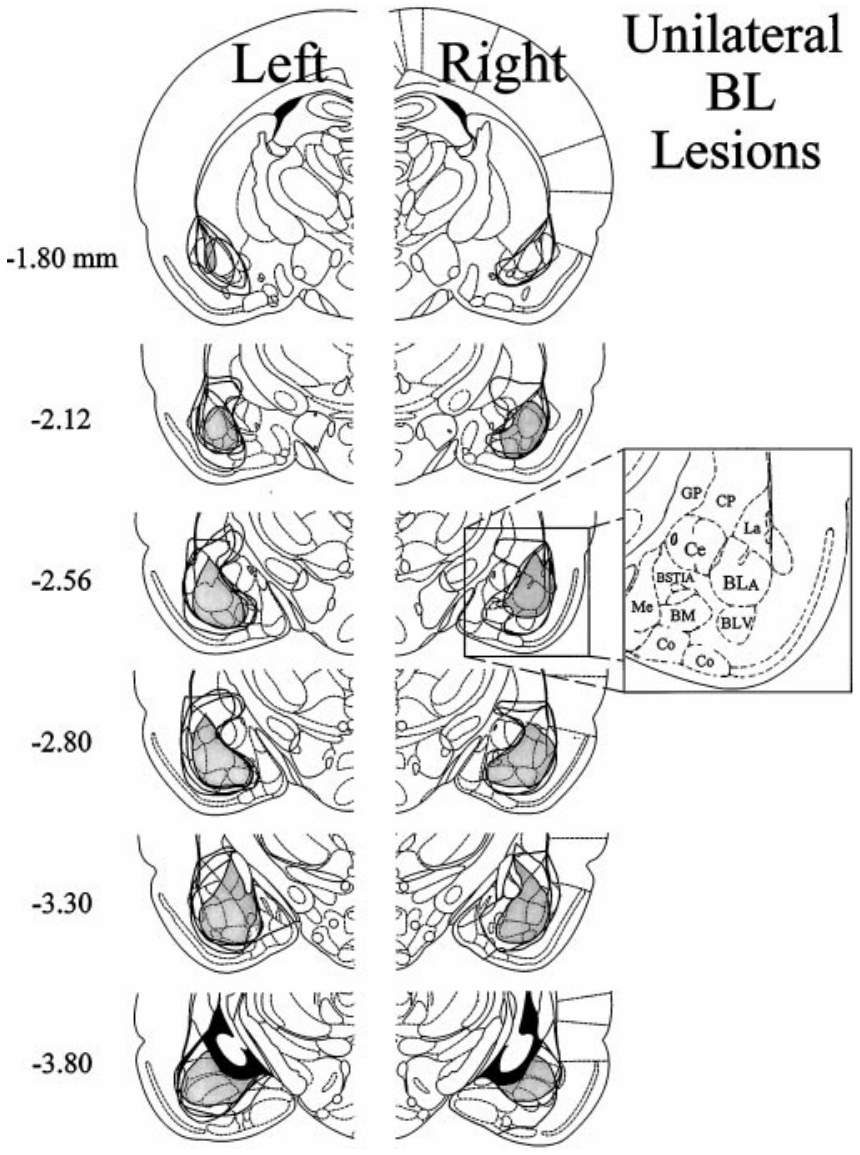

Figure 6. Histological results of Experiment 2: unilateral BL lesions, morphine and ipsilateral formalin. Representations of six coronal sections through the rat forebrain are shown in sequence from anterior to posterior. The numbers in the left margin indicate millimeters posterior to bregma. The closed curves illustrate the borders of BL lesions $(n=7)$, as determined by the extent of neuronal cell loss and gliosis. The lesion area common to all rats in each hemisphere is shown as light shading. Note that four rats had lesions placed in the left cerebral hemisphere, whereas the other three had lesions placed in the right cerebral hemisphere. Adapted from Paxinos and Watson (1986). Amygdaloid areas: $C e$, central nucleus; $B L A$, basolateral nucleus, anterior; $B L V$, basolateral nucleus, ventral; $B S T I A$, bed nucleus of the stria terminalis, intra-amygdaloid division; $M e$, medial nucleus; $B M$, basomedial nucleus; $C o$, cortical amygdaloid nuclei. Extra-amygdaloid areas: $G P$, globus pallidus; $C P$, caudate-putamen.

Contralateral formalin and systemic morphine. The extent of neuronal cell loss corresponding to unilateral BL lesion rats treated with morphine plus contralateral formalin $(n=8)$ is illustrated in Figure 7. The pattern of neuronal cell loss was similar to that in $\mathrm{BL}$ lesion rats treated with morphine plus ipsilateral formalin (see above). Note that four rats had lesions of the left BL, whereas another four rats had lesions of the right BL. The light shading in Figure 7 indicates a damaged area common to all rats with $\mathrm{BL}$ lesions in the right or left hemisphere. In all eight cases, there was substantial neuronal cell loss to at least $80 \%$ of the BL. In most rats this was accompanied by damage to large portions of the lateral amygdaloid nucleus and smaller portions of

figure to illustrate clearly that a unilateral Ce lesion did not affect baseline nociceptive responses when formalin was delivered to the hindpaw ipsilateral to the lesion. 


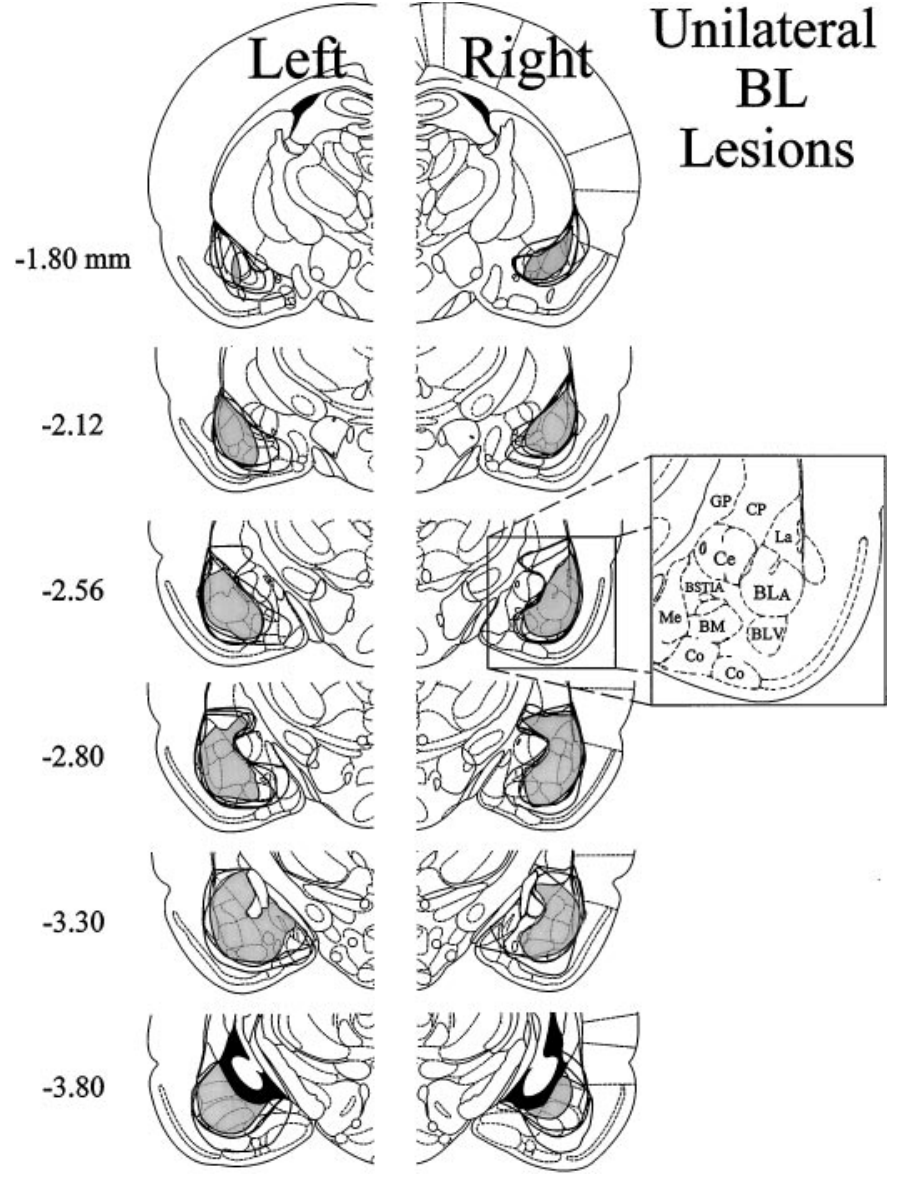

Figure 7. Histological results of Experiment 2: unilateral BL lesions, morphine and contralateral formalin. Representations of six coronal sections through the rat forebrain are shown in sequence from anterior to posterior. The numbers in the left margin indicate millimeters posterior to bregma. The closed curves illustrate the borders of BL lesions $(n=8)$, as determined by the extent of neuronal cell loss and gliosis. The lesion area common to all rats in each hemisphere is shown as light shading. Note that four rats had lesions placed in the left cerebral hemisphere, whereas the other four had lesions placed in the right cerebral hemisphere. Adapted from Paxinos and Watson (1986). Amygdaloid areas: $C e$, central nucleus; $B L A$, basolateral nucleus, anterior; $B L V$, basolateral nucleus, ventral; $B S T I A$, bed nucleus of the stria terminalis, intra-amygdaloid division; $M e$, medial nucleus; $B M$, basomedial nucleus; $C o$, cortical amygdaloid nuclei. Extra-amygdaloid areas: $G P$, globus pallidus; $C P$, = caudate-putamen.

adjacent piriform cortex and overlying caudate-putamen. In all cases, damage extended into the lateral portion of the $\mathrm{Ce}$, although in six cases this damage was very slight. In the other two cases the Ce was damaged by $<10 \%$.

\section{Combined histological data from Experiments 1 and 2}

The histological results depicted in Figures 1 and 6 are combined in Figure 8 to show the unilateral lesions that reduced morphine antinociception (Ce lesions, dark shading) in relation to the unilateral lesions that failed to reduce morphine antinociception (BL lesions, light shading) when formalin was administered to the hindpaw ipsilateral to the lesion.

\section{Nociceptive and locomotor activity scores: unilateral BL-treated rats}

Ipsilateral formalin and systemic morphine. Figure 9 shows rating scale (Fig. 9A), flinch (Fig. 9B), and horizontal locomotor activity (Fig. 9C) scores of the first group of BL-treated rats in Experi-

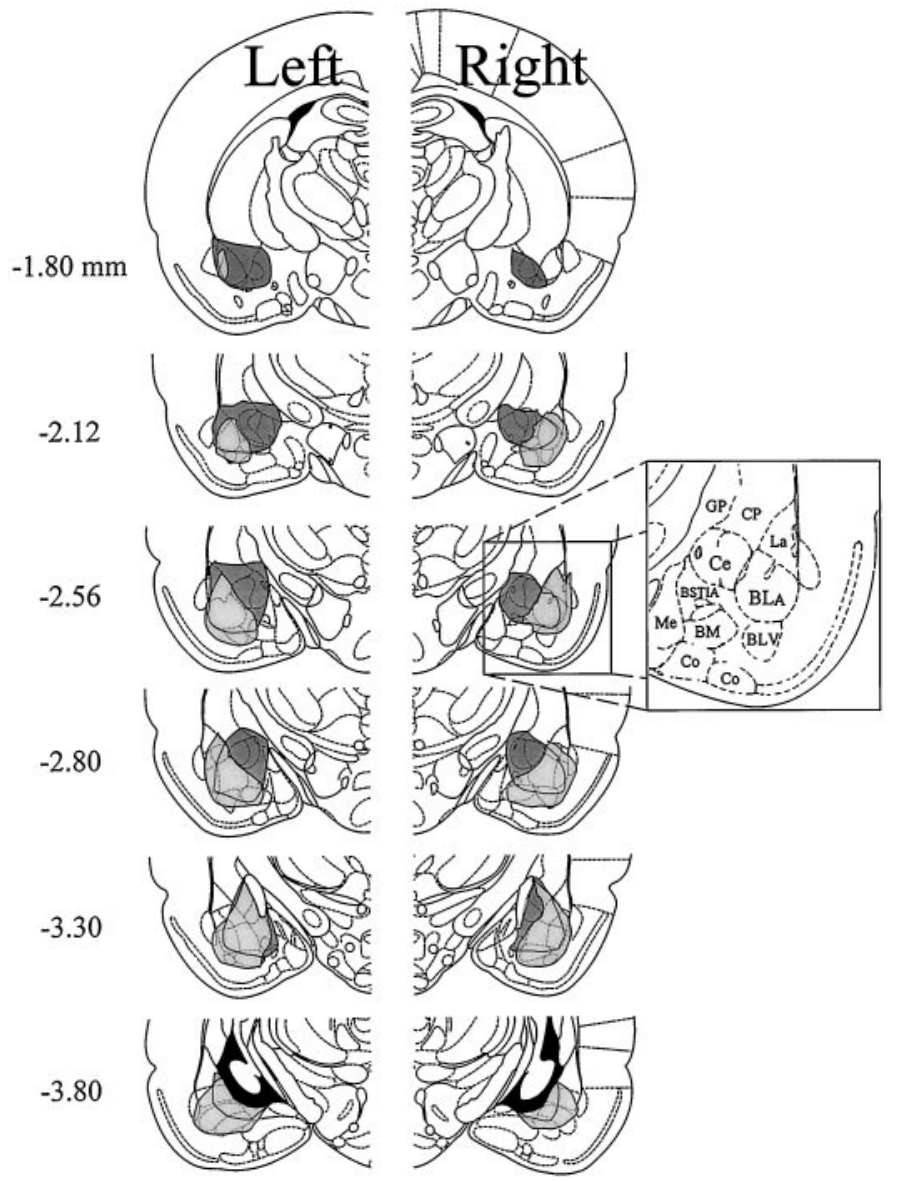

Figure 8. Combined histological results of Experiments 1 and 2 (unilateral $\mathrm{Ce}$ or unilateral BL lesions combined with morphine plus ipsilateral formalin). The histological results depicted in Figures 1 and 6 are combined into a composite representation of the unilateral lesions that reduced morphine antinociception (lesions that included the Ce; see Fig. 3) and the unilateral lesions that failed to reduce morphine antinociception (BL lesions; see Fig. 9) when formalin was administered to the hindpaw ipsilateral to the lesion. The numbers in the left margin indicate millimeters posterior to bregma. The dark shading in each hemisphere indicates the lesion area common to rats in the Ce lesion group of Experiment 1. The lesion area common to rats in the BL lesion group of Experiment 2 is shown as light shading in each hemisphere. Adapted from Paxinos and Watson (1986). Amygdaloid areas: $C e$, central nucleus; $B L A$, basolateral nucleus, anterior; $B L V$, basolateral nucleus, ventral; $B S T I A$, bed nucleus of the stria terminalis, intra-amygdaloid division; $M e$, medial nucleus; $B M$, basomedial nucleus; $\mathrm{Co}=$ cortical amygdaloid nuclei. Extra-amygdaloid areas: $G P$, globus pallidus; $C P$, caudate-putamen.

ment 2. These rats received a subcutaneous injection of morphine followed $5 \mathrm{~min}$ later by injection of formalin into the hindpaw ipsilateral to their BL treatment (either NMDA or vehicle). Rats in this group were tested on another occasion with a subcutaneous injection of saline followed 5 min later by injection of formalin into the hindpaw contralateral to their BL treatment.

An ANOVA performed on the rating scale scores revealed a significant main effect of systemic drug treatment in BL-treated rats $\left(F_{(1,13)}=2.11 .27 ; p<0.0001\right)$ but no significant main effect of lesion $\left(F_{(1,13)}=2.176 ; p>0.05\right)$. Furthermore, no interaction was detected between systemic drug treatment and lesion $\left(F_{(1,13)}\right.$ $=0.11467 ; p>0.05)$, nor was a three-way interaction detected among systemic drug treatment, lesion, and time $\left(F_{(9,117)}=\right.$ $0.5425 ; p>0.05)$. The results indicate that morphine produced 

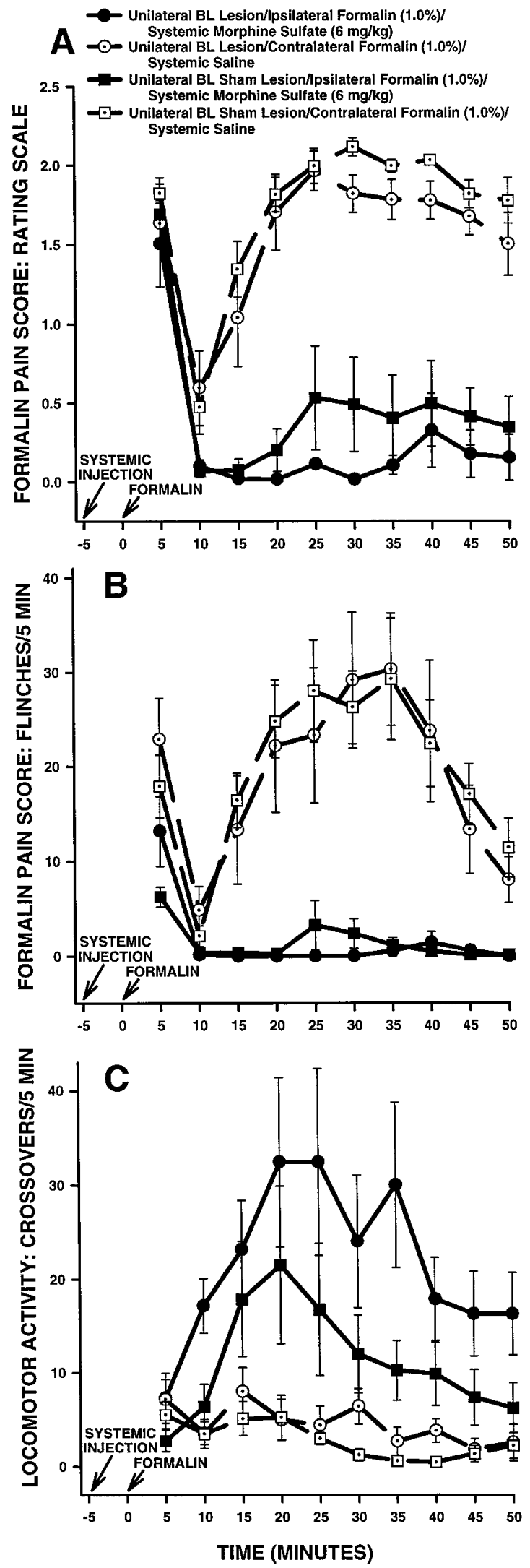

Figure 9. Average nociceptive and horizontal locomotor activity scores of unilateral BL-treated rats in Experiment 2: unilateral BL lesions, morphine and ipsilateral formalin. Error bars indicate SEM. In this experiment, unilateral $\mathrm{BL}$ lesion rats treated with morphine received a formalin injection in the hindpaw ipsilateral to their BL lesion. Rating significantly lower rating scale scores than saline in BL-treated rats and further indicate that rating scale scores were not different between BL sham lesion and BL lesion rats (Fig. 9A).

Flinch scores obtained from the same group of unilateral BLtreated rats are shown in Figure $9 B$. The analysis of flinch scores yielded a pattern of results similar to that obtained with the rating scale method (Fig. 9, compare $A, B$ ).

Horizontal locomotor activity scores obtained from the same group of unilateral BL-treated rats are shown in Figure 9C. An ANOVA performed on these scores revealed a significant main effect of systemic drug treatment $\left(F_{(1,13)}=19.25842 ; p<0.05\right)$, indicating that morphine produced significantly higher horizontal locomotor activity scores than saline in BL-treated rats (Fig. 9C). A significant main effect of lesion was not detected, however $\left(F_{(1,13)}=3.9695 ; p>0.05\right)$, nor was there a significant interaction between lesion and systemic drug treatment $\left(F_{(1,13)}=2.36782\right.$; $p>0.05)$, indicating that horizontal locomotor activity scores were not significantly different overall between unilateral BL lesion and unilateral BL sham lesion rats (Fig. 9C).

Contralateral formalin and systemic morphine. Figure 10 shows rating scale (Fig. 10A), flinch (Fig. 10B), and horizontal locomotor activity (Fig. 10C) scores of a second group of BL-treated rats in Experiment 2. These rats received a subcutaneous injection of morphine followed $5 \mathrm{~min}$ later by injection of formalin into the hindpaw contralateral to their BL treatment (either NMDA or vehicle). Rats in this group were tested on another occasion with a subcutaneous injection of saline followed 5 min later by injection of formalin into the hindpaw ipsilateral to their BL treatment.

An ANOVA performed on rating scale scores revealed a significant interaction among lesion, systemic drug, and time in unilateral BL-treated rats $\left(F_{(9,126)}=2.10 ; p<0.05\right)$. Tukey's HSD tests detected no significant differences in baseline (i.e., systemic saline) scores between BL lesion and BL sham lesion rats (Fig. $10 A ; p>0.05$ at all time points). Morphine produced significantly lower rating scale scores, compared with saline, in both $\mathrm{BL}$ sham lesion and $\mathrm{BL}$ lesion rats during the second $(10-50$ min) phase of the formalin test (Fig. 10A; Tukey's HSD tests, $p<$ 0.01 at all time points). Furthermore, at most time points there were no significant differences in rating scale scores between BL sham lesion rats treated with morphine and BL lesion rats treated with morphine (Fig. 10A; Tukey's HSD tests, $p>0.05$ ). The one exception to this pattern was the interval 45-50 min after formalin injection, when BL lesion rats showed significantly higher rating scale scores than $\mathrm{BL}$ sham lesion rats (Fig. 10A; Tukey's HSD test, $p<0.05$ ).

Flinch scores obtained from the same group of BL-treated rats are shown in Figure $10 \mathrm{~B}$. The analysis of flinch scores yielded a pattern of results similar to that obtained with the rating scale method (Fig. 10, compare $A, B$ ).

scale nociceptive scores are shown in $A$, flinch nociceptive scores are shown in $B$, and horizontal locomotor activity scores are shown in $C$. Note the similar pattern of results obtained with the rating scale and flinchfrequency methods of nociceptive scoring. There were no significant differences in baseline (i.e., systemic saline) nociceptive or horizontal locomotor activity scores at any time point between unilateral BL lesion rats and unilateral BL sham lesion rats. In unilateral BL sham lesion rats, morphine sulfate $(6 \mathrm{mg} / \mathrm{kg}$, s.c.) produced significant antinociception compared with saline at most time points. Unlike Ce lesion rats that received morphine and ipsilateral formalin (Fig. 3), unilateral BL lesions did not affect morphine-induced suppression of pain derived from the ipsilateral hindpaw. 

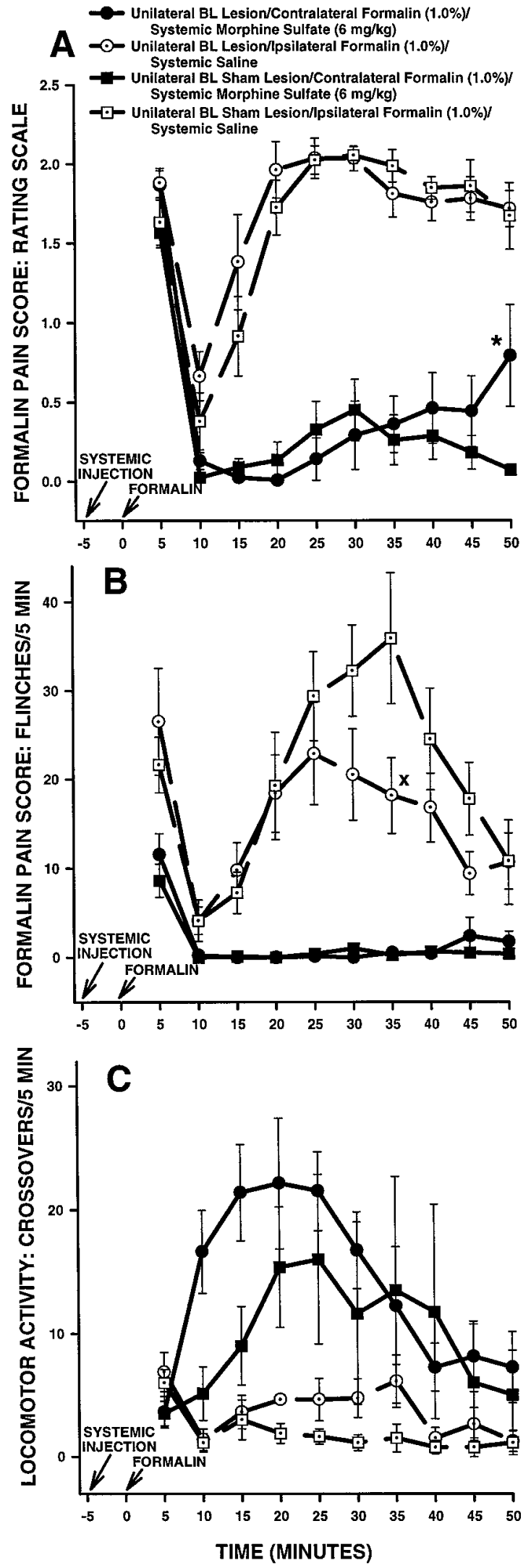

Figure 10. Average nociceptive and horizontal locomotor activity scores of unilateral BL-treated rats in Experiment 2: unilateral BL lesions, morphine and contralateral formalin. Error bars indicate SEM. In this experiment, unilateral $\mathrm{BL}$ lesion rats treated with morphine received a formalin injection in the hindpaw contralateral to their BL lesion. Rating
Horizontal locomotor activity scores obtained from the same group of BL-treated rats are shown in Figure 10C. An ANOVA performed on these scores revealed a significant main effect of systemic drug treatment $\left(F_{(1,14)}=11.65 ; p<0.01\right)$, indicating that morphine produced significantly higher horizontal locomotor activity scores than saline in BL-treated rats (Fig. 10C). A significant main effect of lesion was not detected, however $\left(F_{(1,14)}=\right.$ $684.45 ; p>0.05)$, nor was there a significant interaction between lesion and systemic drug treatment $\left(F_{(1,14)}=0.1709 ; p>0.05\right)$, indicating that horizontal locomotor activity scores were not significantly different overall between unilateral BL lesion and unilateral BL sham lesion rats.

\section{EXPERIMENT 3}

The results of Experiments 1 and 2 suggest that a unilateral excitotoxin-induced lesion of a portion of amygdala that includes the Ce strongly reduces the ability of $6 \mathrm{mg} / \mathrm{kg}$ morphine sulfate to suppress formalin-induced nociception derived from the hindpaw ipsilateral, but not contralateral, to the lesion. In Experiment 1, separate groups of lesion rats were used to determine the effects of unilateral Ce lesions on morphine antinociception, depending on which hindpaw (ipsilateral or contralateral) was to receive formalin. Separate groups of rats were used because it was deemed necessary to examine both baseline behavioral responses to formalin and effects of morphine in each rat while limiting the number of formalin test sessions per hindpaw to one. The data in Figure 4 strongly suggest that unilateral Ce lesions do not affect the ability of morphine to suppress formalin-induced nociception derived from the hindpaw contralateral to the lesion. It remains possible, however, that subtle differences in the extent of lesions between the two Ce lesion groups in Experiment 1 account for the differences observed (compare Figs. 1, 2). Accordingly, Experiment 3 involved using the same rat to determine the effects of a unilateral $\mathrm{Ce}$ lesion on the ability of morphine to suppress nociception derived from the ipsilateral versus contralateral hindpaw. In this way, differences in lesion extent between the two $\mathrm{Ce}$ lesion groups of Experiment 1 could be controlled for.

\section{Materials and methods}

The methods used in this experiment were identical to those used in Experiment 1 with the following exceptions: (1) only one group each of $\mathrm{Ce}$ lesion and $\mathrm{Ce}$ sham lesion rats was prepared; and (2) rats received an injection of morphine sulfate $(6 \mathrm{mg} / \mathrm{kg}$, s.c.) preceding both formalin test sessions, with a different hindpaw used on each occasion. Rats in this experiment did not receive a formalin test session involving systemic injection of saline. The side of the unilateral lesion (left or right hemisphere) and the order of hindpaw formalin injection (ipsilateral hindpaw in the first session followed by contralateral hindpaw in the second session or vice versa) were counterbalanced within each group.

scale nociceptive scores are shown in $A$, flinch nociceptive scores are shown in $B$, and horizontal locomotor activity scores are shown in $C$. Note the similar pattern of results obtained with the rating scale and flinchfrequency methods of nociceptive scoring. There were no significant differences in baseline (i.e., systemic saline) nociceptive or horizontal locomotor activity scores at any time point between unilateral BL lesion rats and unilateral BL sham lesion rats. In both unilateral BL sham lesion and unilateral BL lesion rats, morphine sulfate $(6 \mathrm{mg} / \mathrm{kg}$, s.c.) suppressed pain associated with injection of formalin into the contralateral hindpaw. $A,{ }^{*} p<0.01$, Tukey's HSD test, compared with unilateral BL sham lesion rats treated with systemic morphine. $B,{ }^{X} p<0.05$, Wilcoxon signed-rank test, compared with unilateral BL sham lesion rats treated with systemic saline. 

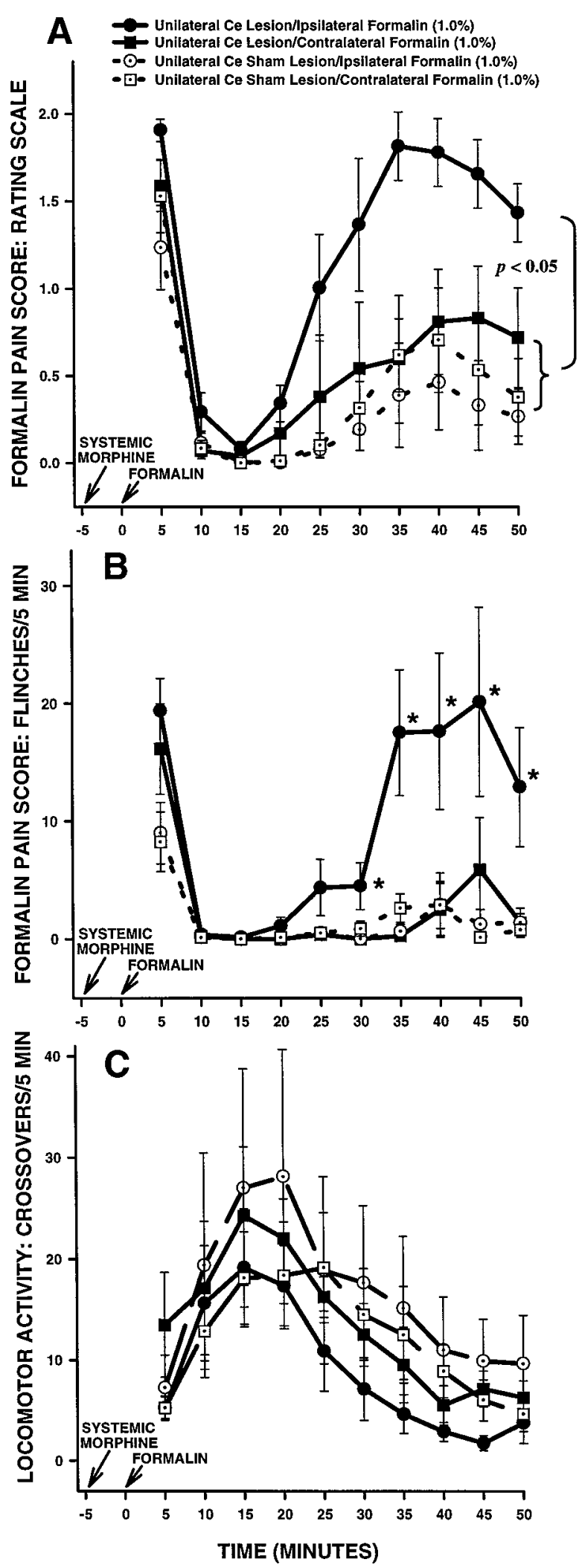

Figure 11. Average nociceptive and horizontal locomotor activity scores of unilateral Ce-treated rats in Experiment 3. Error bars indicate SEM. Rating scale nociceptive scores are shown in $A$, flinch nociceptive scores are shown in $B$, and horizontal locomotor activity scores are shown in $C$. In this experiment, Ce-treated rats (sham lesion and lesion) received systemic morphine and intraplantar formalin on two separate occasions. On one occasion, formalin was delivered to the hindpaw ipsilateral to the

\section{Results}

Histology

The unilateral Ce lesions of Experiment $3(n=8)$ were similar in size and extent to those presented in Figure 1. The amygdala in the left cerebral hemisphere was lesioned in four rats, whereas the amygdala in the right hemisphere was lesioned in another four rats.

\section{Nociceptive and locomotor activity scores}

Rating scale scores of unilateral Ce-treated rats in Experiment 3 are shown in Figure 11 $A$. An ANOVA performed on rating scale scores revealed a significant interaction between lesion and systemic drug treatment in unilateral Ce-treated rats $\left(F_{(1,14)}=\right.$ 5.277; $p<0.05)$. Further analysis of the significant interaction revealed no significant differences between $\mathrm{Ce}$ sham lesion rats treated with systemic morphine plus ipsilateral formalin and $\mathrm{Ce}$ sham lesion rats treated with systemic morphine plus contralateral formalin (Fig. 11 $A$; Tukey's HSD test, $p>0.05$ ). Furthermore, no differences were detected between Ce lesion rats treated with morphine plus contralateral formalin and rats in either of the $\mathrm{Ce}$ sham lesion groups (Fig. 11 $A$; Tukey's HSD tests, $p>0.05$ ). Significant differences were detected, however, between Ce lesion rats treated with morphine plus ipsilateral formalin and all other groups in the experiment. Ce lesion rats treated with morphine plus ipsilateral formalin showed significantly higher rating scale scores than all other groups (Fig. 11 $A$; Tukey's HSD tests, $p<0.05)$.

Flinch scores of unilateral Ce-treated rats in Experiment 3 are shown in Figure $11 B$. The analysis of flinch scores yielded a pattern of results similar to that obtained with the rating scale method (Fig. 11, compare $A, B$ ).

Horizontal locomotor activity scores of unilateral Ce-treated rats in Experiment 3 are shown in Figure 11C. An ANOVA performed on these scores revealed neither a significant main effect of lesion $\left(F_{(1,14)}=0.9836 ; p>0.05\right)$ nor a significant interaction between lesion and systemic drug treatment $\left(F_{(1,14)}=1.482 ; p>\right.$ 0.05). The data indicate that unilateral Ce lesions did not alter morphine-induced increases in horizontal locomotor activity.

\section{EXPERIMENT 4}

Experiments 1 and 3 were performed using a single dose of morphine sulfate $(6 \mathrm{mg} / \mathrm{kg})$ and a single concentration of formalin $(1.0 \%)$. It is of interest, therefore, to know whether the results of these experiments are generalizable to other doses of morphine sulfate and other concentrations of formalin. Accordingly, dose- and concentration-effect curves were constructed in Experiment 4 for both unilateral $\mathrm{Ce}$ lesion and unilateral $\mathrm{Ce}$ sham lesion rats. For the dose-effect curves, the dose of systemic

Ce treatment (lesion or sham lesion), and on the other occasion formalin was delivered to the contralateral hindpaw. Note the similar pattern of results obtained with the rating scale and flinch-frequency methods of nociceptive scoring. Under morphine, there were no significant differences in nociceptive scores between either group of unilateral Ce sham lesion rats and unilateral Ce lesion rats treated with contralateral formalin. In unilateral $\mathrm{Ce}$ lesion rats treated with ipsilateral formalin, however, morphine sulfate $(6 \mathrm{mg} / \mathrm{kg}$, s.c.) produced significantly less antinociception compared with all other groups. As was the case in Experiment 1 (Fig. 3), this effect was dissociable from the effects of morphine on horizontal locomotor activity, because morphine-induced increases in locomotor activity were unaffected by unilateral Ce lesions $(C) . B,{ }^{*} p<$ 0.05 , Mann-Whitney $U$ test, compared with all other groups. 
A

- Unilateral Ce Sham Lesion/Ipsilateral Formalin (1.0\%) Unilateral Ce Lesion/lpsilateral Formalin (1.0\%)

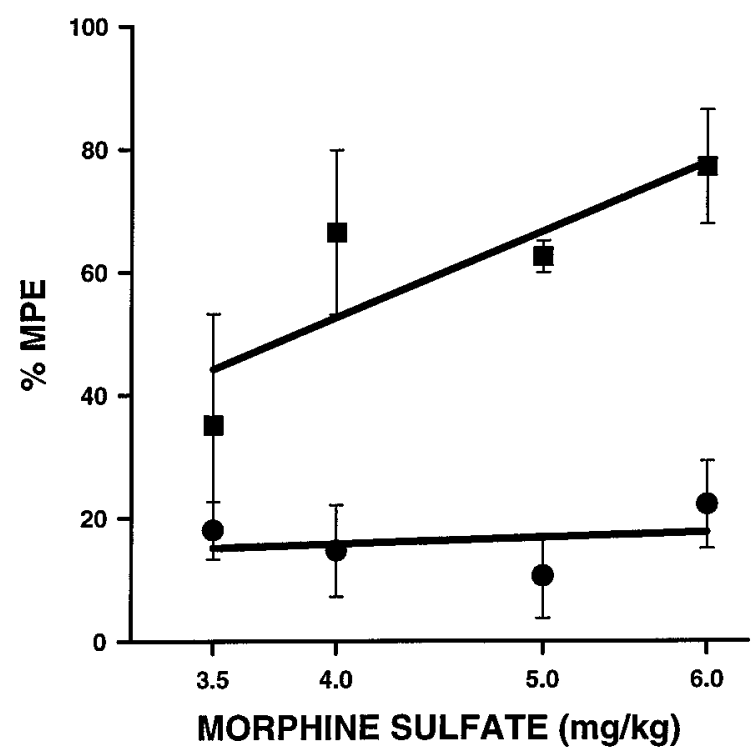

B

- Unilateral Ce Sham Lesion/Contralateral Formalin (1.0\%) Unilateral Ce Lesion/Contralateral Formalin (1.0\%)

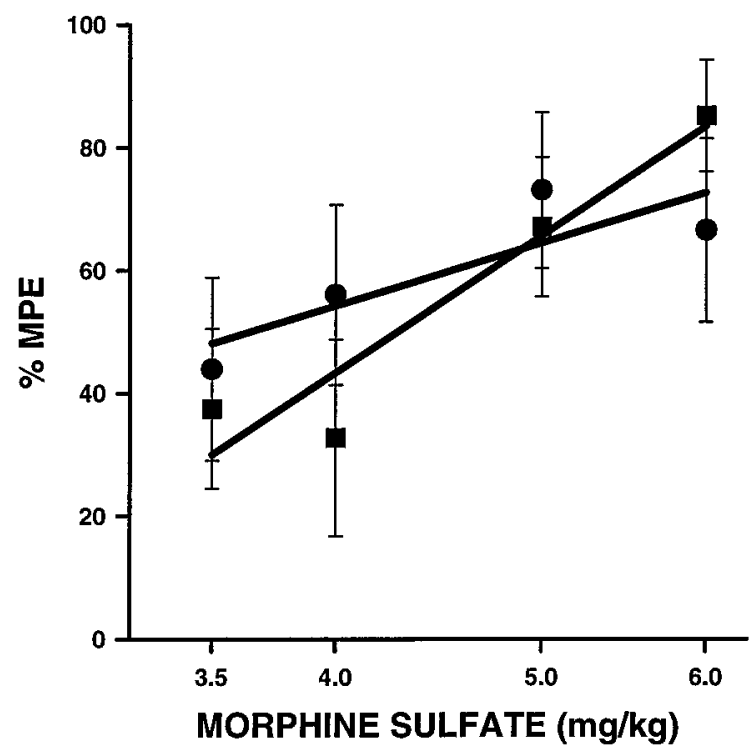

Figure 12. Dose-effect relations for morphine in rats with unilateral Ce lesions or unilateral Ce sham lesions $(n=5-8$ per group). For these curves, the dose of morphine was varied, whereas the concentration of formalin injected into either the ipsilateral $(A)$ or contralateral $(B)$ hindpaw was held constant at $1.0 \%$. Rating scale nociceptive scores were averaged across the second phase of the formalin test for all rats. The mean second phase nociceptive score for systemic saline-treated control rats (either lesion or sham lesion) was used as $E_{\min }$ for calculation of percentage of maximum possible antinociceptive effect (\%MPE; see Experiment 4, Materials and methods).

morphine was varied, whereas the concentration of formalin injected into either the ipsilateral or contralateral hindpaw was held constant at $1.0 \%$. For the concentration-effect curves, the concentration of formalin injected into either the ipsilateral or contralateral hindpaw was varied, whereas the dose of systemic morphine sulfate was held constant at $5 \mathrm{mg} / \mathrm{kg}$.

It should be noted that no attempt was made to overcome the lateralized deficit in morphine antinociception by raising doses of morphine above $6 \mathrm{mg} / \mathrm{kg}$ (i.e., to show a rightward shift in the morphine dose-effect curve). This was not attempted because higher morphine doses result in significant catalepsy and locomotor depression.

\section{Materials and methods}

The methods used for the preparation of unilateral Ce lesions and unilateral Ce sham lesions were identical to those used in Experiments 1 and 3. The formalin test protocol used in this experiment was similar to that used in Experiment 3. One week after surgery, each rat was assigned to a group corresponding to a single morphine dose and a single formalin concentration. The rat then underwent two formalin test sessions separated by $7 \mathrm{~d}$, with a different hindpaw used on each occasion. The order of hindpaw formalin injection (ipsilateral hindpaw in the first session followed by contralateral hindpaw in the second session or vice versa) was counterbalanced within each group. Locomotor activity was not monitored in this experiment.

Statistical analyses. Nociceptive rating scale scores for each morphinetreated rat were averaged across the formalin test second phase (20-50 min after formalin injection) and converted to percentage of maximum possible antinociceptive effect (\% MPE) using the following formula:

$$
\% \mathrm{MPE}=\left(E-E_{\min }\right) \times 100 /\left(E_{\max }-E_{\min }\right)
$$

The mean rating scale score (second phase) for systemic salinetreated control rats (either lesion or sham lesion) injected with a particular concentration of formalin was used as $E_{\min }$, and $E_{\max }$ was defined as 0 (i.e., absence of any pain-related behaviors). Log dose-effect or log concentration-effect curves were constructed using least-squares linear regression. $\mathrm{MPE}_{50}$ values (dose resulting in $50 \%$ of the maximum possible antinociceptive effect) plus $95 \%$ confidence intervals $\left(\mathrm{CI}_{95 \%}\right)$ were calculated for the doseeffect curves, where appropriate, using formulas provided by Tallarida and Murray (1987). The data were analyzed further using ANOVA as appropriate.

\section{Results}

Morphine dose-effect curves for unilateral Ce lesion and unilateral Ce sham lesion rats are shown in Figure $12(n=5-8$ per group). For these curves, the dose of morphine was varied, whereas the concentration of formalin injected into either the ipsilateral or contralateral hindpaw was held constant at $1.0 \%$. Figure $12 A$ shows dose-effect curves relating to formalin administered ipsilateral to the Ce treatment, and Figure $12 \mathrm{~B}$ shows dose-effect curves relating to formalin administered contralateral to the Ce treatment. Baseline (i.e., systemic saline) pain scores were similar for unilateral $\mathrm{Ce}$ saline and unilateral $\mathrm{Ce}$ sham lesion rats. Morphine produced dose-dependent antinociception in unilateral $\mathrm{Ce}$ sham lesion rats regardless of whether formalin was administered to the hindpaw ipsilateral (Fig. $12 A ; \mathrm{MPE}_{50}$, $4.30 \mathrm{mg} / \mathrm{kg} ; \mathrm{CI}_{95 \%}, 3.83-4.83$ ) or contralateral (Fig. 12B; $\mathrm{MPE}_{50}$, $\left.4.16 \mathrm{mg} / \mathrm{kg} ; \mathrm{CI}_{95 \%}, 3.07-5.64\right)$ to the unilateral Ce sham lesion. These $\mathrm{MPE}_{50}$ values did not differ significantly from each other (Student's $t$ test, $p>0.05$ ). In unilateral Ce lesion rats, morphine dose-dependently reduced nociceptive behaviors when formalin was injected into the hindpaw contralateral to the Ce lesion (Fig. $\left.12 \mathrm{~B} ; \mathrm{MPE}_{50}, 4.27 \mathrm{mg} / \mathrm{kg} ; \mathrm{CI}_{95 \%}, 2.70-6.74\right)$. When formalin was injected into the hindpaw ipsilateral to the Ce lesion, however, 

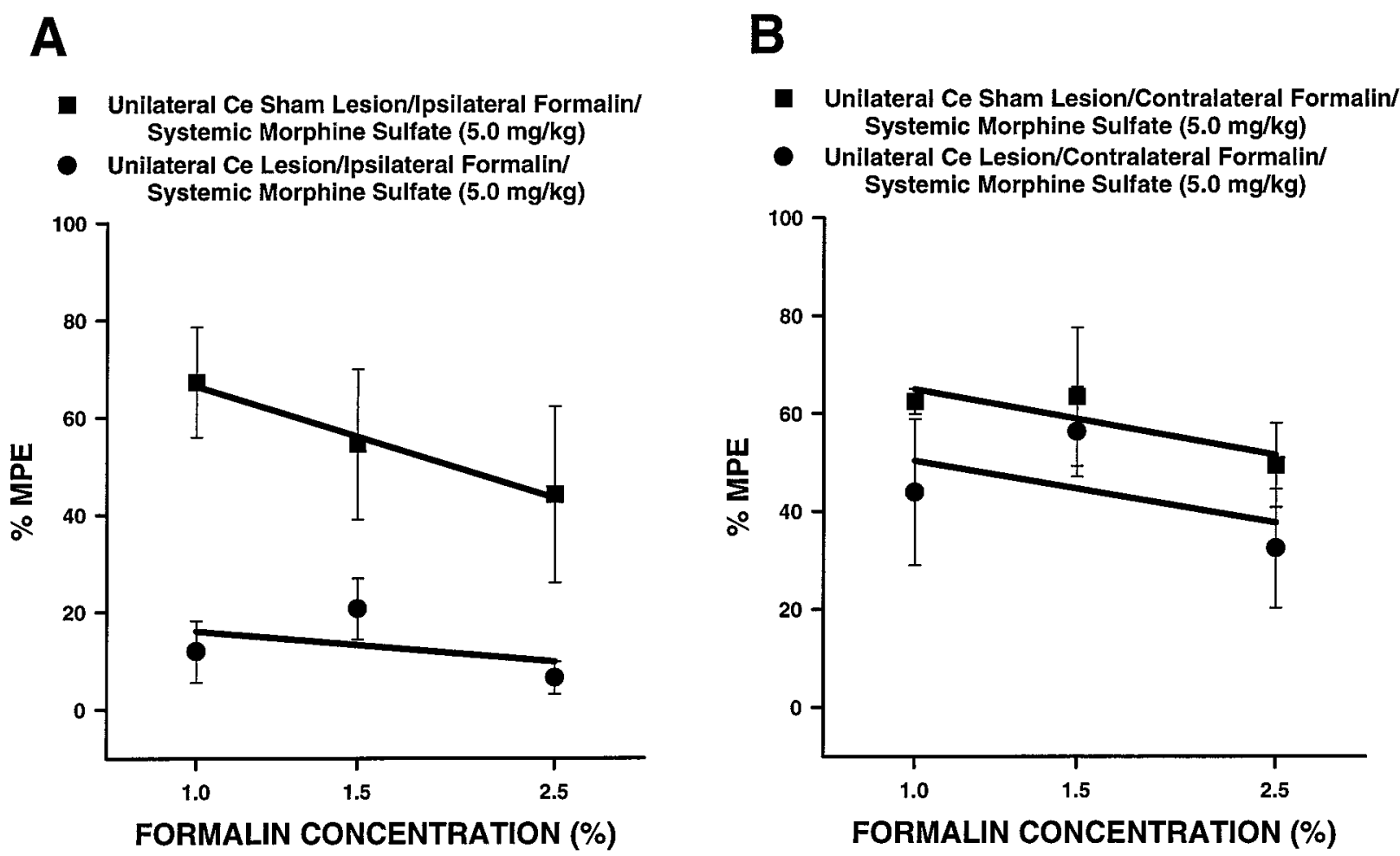

Figure 13. Concentration-effect relations for morphine in rats with unilateral Ce lesions or unilateral Ce sham lesions $(n=6$ per group). For these curves, the concentration of formalin injected into either the ipsilateral $(A)$ or contralateral $(B)$ hindpaw was varied, whereas the dose of morphine was held constant at $5 \mathrm{mg} / \mathrm{kg}$. Rating scale nociceptive scores were averaged across the second phase of the formalin test for all rats. The mean second phase nociceptive score for systemic saline-treated control rats (either lesion or sham lesion) was used as $E_{\min }$ for calculation of percentage of maximum possible antinociceptive effect (\%MPE; see Experiment 4, Materials and methods).

morphine produced significantly less antinociception than that observed in unilateral Ce sham lesion rats (Fig. $12 A ; F_{(1,43)}=$ 29.99; $p<0.0001$, ANOVA).

Formalin concentration-effect curves for unilateral Ce lesion and unilateral Ce sham lesion rats are shown in Figure $13(n=6$ per group). For these curves, the concentration of formalin was varied, whereas the dose of morphine was held constant at 5 $\mathrm{mg} / \mathrm{kg}$. Figure $13 \mathrm{~A}$ shows concentration-effect curves relating to formalin administered ipsilateral to the Ce treatment, and Figure $13 B$ shows concentration-effect curves relating to formalin administered contralateral to the Ce treatment. Baseline (i.e., systemic saline) pain scores were similar for unilateral Ce saline and unilateral $\mathrm{Ce}$ sham lesion rats at all concentrations of formalin tested. In unilateral Ce sham lesion rats, morphine $(5 \mathrm{mg} / \mathrm{kg})$ produced equivalent antinociception at all concentrations of formalin, regardless of whether formalin was injected into the hindpaw ipsilateral (Fig. 13A) or contralateral (Fig. 13B) to the $\mathrm{Ce}$ sham lesion. In unilateral $\mathrm{Ce}$ lesion rats, morphine $(5 \mathrm{mg} / \mathrm{kg})$ produced antinociception in a manner similar to that seen in $\mathrm{Ce}$ sham lesion rats when formalin was injected into the hindpaw contralateral to the Ce lesion (Fig. $13 B ; F_{(1,30)}=2.48 ; p=0.1255$, ANOVA). When formalin was injected into the hindpaw ipsilateral to the Ce lesion, however, morphine produced significantly less antinociception than that observed in unilateral $\mathrm{Ce}$ sham lesion rats (Fig. $13 A ; F_{(1,30)}=20.44 ; p<0.0001$, ANOVA).

The data presented in Figures 12 and 13 indicate that the results obtained in Experiments 1 and 3 are generalizable across a number of different morphine doses and formalin concentrations.

\section{EXPERIMENT 5}

Experiments 1-4 were performed using a single method of inactivation (i.e., excitotoxin-induced lesions), the limitations of which we have discussed previously (Manning and Mayer, 1995b; also see Discussion below). It is of interest, therefore, to know whether the results of Experiments 1, 3, and 4 are generalizable to another method of inactivating Ce neurons. Accordingly, Experiment 5 involved determining whether temporary, unilateral inactivation of the $\mathrm{Ce}$ with the $\mathrm{GABA}_{\mathrm{A}}$ agonist muscimol (Martin, 1991) would reduce the ability of morphine sulfate to suppress formalin-induced nociception derived from the ipsilateral hindpaw. Locomotor activity was not monitored in this experiment.

\section{Materials and methods}

Surgery. Rats were anesthetized as described in Experiment 1. A stainless steel guide cannula (23 gauge) was stereotaxically placed unilaterally $2 \mathrm{~mm}$ above the Ce according to the atlas of Paxinos and Watson (1986) [coordinates: AP, $-2.5 \mathrm{~mm}$ (posterior to bregma); lateral, $\pm 4.3 \mathrm{~mm}$; and ventral $6.3 \mathrm{~mm}$ ]. A stainless steel stylet (00 inject pin), extending just past the tip of the guide cannula, kept it free of debris during the surgical recovery period. The recovery period lasted $7 \mathrm{~d}$.

Experimental design. After surgery, animals were randomly chosen for inclusion in either an intra-Ce muscimol treatment group or an intra-Ce saline treatment group. Each of these groups in turn underwent two formalin test sessions spaced $7 \mathrm{~d}$ apart. The first test session began with a subcutaneous injection of morphine sulfate $(4 \mathrm{mg} / \mathrm{kg}$ ) followed $5 \mathrm{~min}$ later by injection of formalin $(1.5 \%, 50 \mu \mathrm{l})$ under the plantar surface of one hindpaw. The second test session was identical to the first, except that the other hindpaw was used for formalin injection. After the formalin injection, the rat was placed in a Plexiglas observation box (see Experiment 1, Nociceptive testing) to await the microinjection proce- 


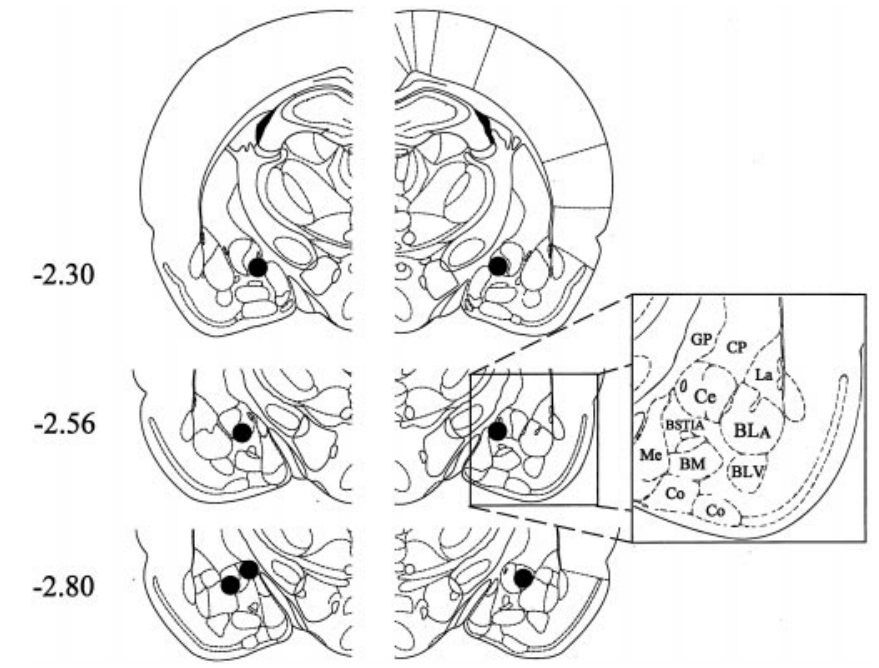

Figure 14. Histological results of Experiment 5 (unilateral muscimol injection into the $\mathrm{Ce}$ ). Representations of three coronal sections through the rat amygdala are shown in sequence from anterior to posterior. The numbers in the left margin indicate millimeters posterior to bregma. The filled circles in each hemisphere show the approximate positions of the cannula tips corresponding to rats in the intra-Ce muscimol treatment group $(n=7)$. Adapted from Paxinos and Watson (1986). Amygdaloid areas: $C e$, central nucleus; $B L A$, basolateral nucleus, anterior; $B L V$, basolateral nucleus, ventral; $B S T I A$, bed nucleus of the stria terminalis, intra-amygdaloid division; $M e$, medial nucleus; $B M$, basomedial nucleus; $C o$, cortical amygdaloid nuclei. Extra-amygdaloid areas: $G P$, globus pallidus; $C P,=$ caudate-putamen.

dure. Ten minutes after the formalin injection, the stylet was removed from its guide cannula and replaced with a 30 gauge injection cannula extending $2 \mathrm{~mm}$ beyond the tip of the guide cannula. Five minutes after insertion of the injection cannula, the intra-Ce injectate [either muscimol hydrobromide (Research Biochemicals, Natick, MA; $25 \mathrm{ng}$ in $250 \mathrm{nl}$ of $0.9 \%$ saline) or $250 \mathrm{nl}$ of saline alone] was inf used slowly over $5 \mathrm{~min}$. The injection cannula was left in place for an additional 3 min to allow sufficient time for absorption of injectate into local tissue. Scoring of formalin-induced nociceptive behaviors (see Experiment 1, Nociceptive testing) started $25 \mathrm{~min}$ after formalin injection $(2 \mathrm{~min}$ after removal of the injection cannula) and continued for the next $30 \mathrm{~min}$. The cerebral hemisphere chosen for intra-Ce drug infusion (right or left) and the order of hindpaw formalin injection (ipsilateral hindpaw in the first session followed by contralateral hindpaw in the second session or vice versa) were counterbalanced within each group.

After completion of the second formalin test session, rats were perfused through the heart, and their brains were removed and stored in sucrose-formalin (Experiment 1, Histology). The brains were quickly frozen and sliced at $-25^{\circ} \mathrm{C}$. Coronal sections $(20 \mu \mathrm{m}$ thick) were taken through the amygdala and stained with cresyl violet. The tip of the injection cannula was determined using a light microscope. A rat was included for statistical analyses only if its unilateral cannula placement was within the borders of the Ce.

Statistical analyses. Rating scale scores (Experiment 1, Nociceptive testing) collected from $\mathrm{Ce}$-treated rats were analyzed in a three-factor ANOVA (intra-Ce drug treatment $\times$ systemic drug treatment $\times$ time), with systemic drug treatment and time analyzed as repeated measures. Multiple pairwise comparisons were made using Tukey's HSD tests. Flinch scores were analyzed nonparametrically. Independent groups were compared using the Mann-Whitney $U$ test. Related groups were compared using the Wilcoxon signed-rank test.

\section{Results}

Histology

The unilateral placements of inner cannula tips corresponding to intra-Ce muscimol-treated rats $(n=7)$ are shown in Figure 14. Note that the cannula placements of these rats, as well as those corresponding to the intra-Ce saline treated rats $(n=7$; not shown in Fig. 14), were within the borders of the Ce.

\section{Nociceptive scores}

Rating scale scores of the unilateral Ce-treated rats in Experiment 5 are shown in Figure 15A. An ANOVA performed on rating scale scores revealed a significant interaction between intra-Ce drug treatment and systemic drug treatment in unilateral Ce-treated rats $\left(F_{(1,12)}=11.14 ; p<0.01\right)$. Further analysis of the interaction revealed no significant difference between intra-Ce saline rats treated with systemic morphine plus ipsilateral formalin and intra-Ce saline rats treated with systemic morphine plus contralateral formalin (Fig. 15A; Tukey's HSD test, $p>0.05$ ). Furthermore, no differences were detected between intra-Ce muscimol rats treated with morphine plus contralateral formalin and rats in either of the intra-Ce saline groups (Fig. 15A; Tukey's HSD tests, $p>0.05)$. Significant differences were detected, however, between intra-Ce muscimol rats treated with morphine plus ipsilateral formalin and all other groups in the experiment. Intra-Ce muscimol rats treated with morphine plus ipsilateral formalin showed significantly higher rating scale scores than all other groups (Fig. 15A; Tukey's HSD tests, $p<0.01$ ).

Flinch scores of unilateral Ce-treated rats in Experiment 5 are shown in Figure 15B. The analysis of flinch scores yielded a pattern of results similar to that obtained with the rating scale method (Fig. 15, compare $A$ and $B$ ).

\section{DISCUSSION}

\section{Summary of results}

The present data provide the first evidence of a lateralized deficit in opioid antinociception after unilateral inactivation of a specific CNS region. An excitotoxin-induced lesion of the Ce plus adjacent portions of the basolateral amygdaloid complex resulted in a lateralized reduction in morphine-induced antinociception (Figs. 3, 11-13, 15). Lesions restricted to the basolateral amygdaloid complex (i.e., not including the $\mathrm{Ce}$ ) did not have a similar effect (Figs. 6, 7, 9, 10). Because lesions that spared the Ce were ineffective, it is tempting to conclude that the $\mathrm{Ce}$ is the nucleus responsible for the present effects. The present data do not rule out the possibility, however, that damage to both the $\mathrm{Ce}$ and adjacent portions of the basolateral amygdala (i.e., lateral and/or basolateral nucleus) was responsible for the lateralized deficit observed. Nevertheless, these data provide the first behavioral evidence suggesting an ipsilateral topographic organization of descending pain control circuits. The present data also provide the first clear neuroanatomical dissociation between painreducing and locomotor effects of systemically administered morphine.

\section{Complementarity of inactivation techniques used}

For Experiments 1-4, an excitotoxin-induced lesion method was used to inactivate the amygdala. This approach was chosen, instead of using electrolytic lesions, to preserve fibers of passage running through the area of interest (Hastings et al., 1985; Winn et al., 1990, 1991). Furthermore, excitotoxin-induced lesions were chosen over temporary inactivation procedures such as lidocaine (Manning and Mayer, 1995b) or muscimol (Robinson et al., 1993; Krupa et al., 1996) infusion, because each rat underwent two formalin test sessions. To make valid comparisons between data collected during each session, it was necessary that a similar population of amygdala neurons be inactivated on each occasion. Temporary inactivation procedures would have resulted in subtly different inactivation patterns in the amygdala on each test occasion, because of subtle differences in the location of the injection cannula on insertion. 


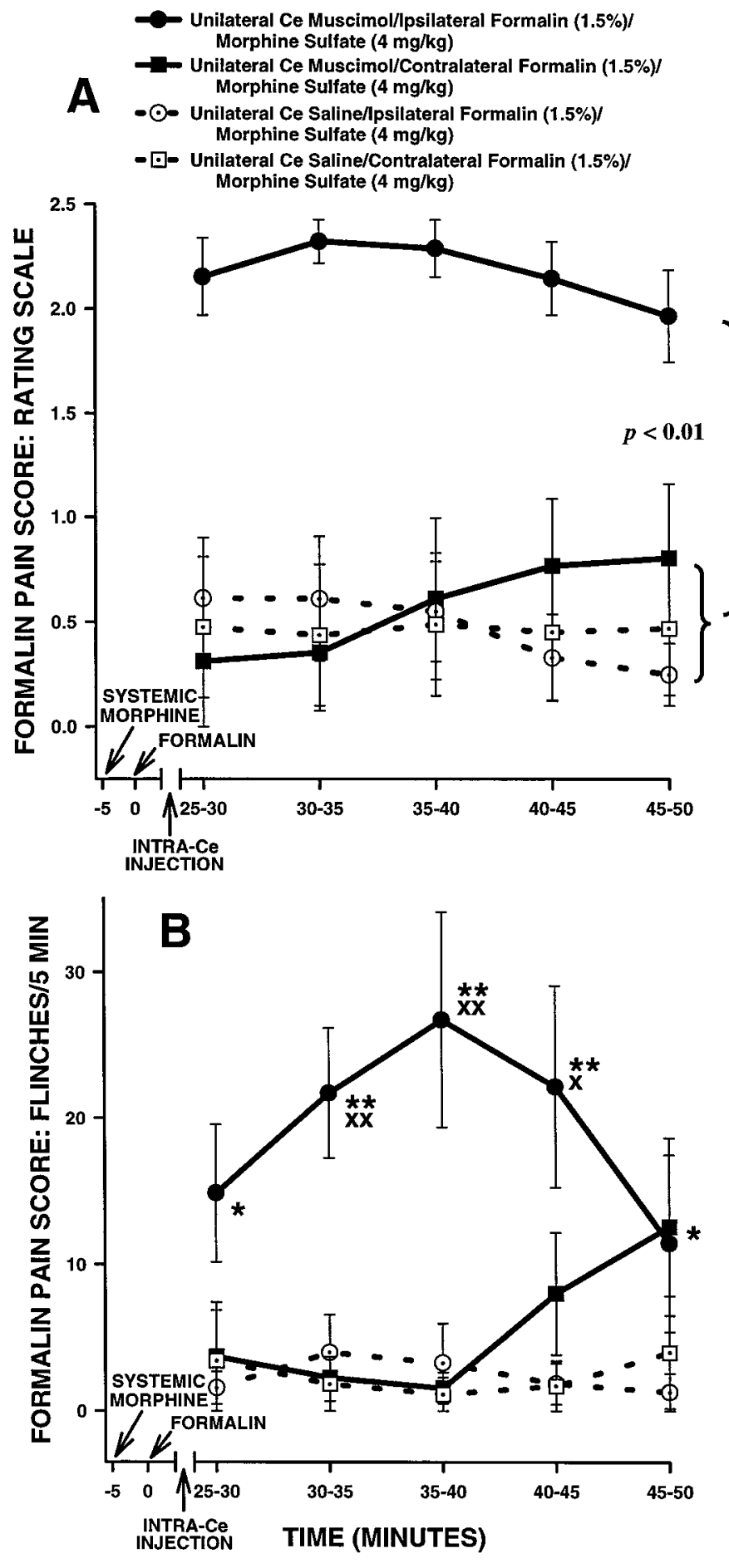

Figure 15. Average nociceptive scores of unilateral Ce-treated rats in Experiment 5. Rating scale nociceptive scores are shown in $A$ and flinch nociceptive scores are shown in $B$. Error bars indicate SEM. In this experiment, Ce-treated rats received systemic morphine and intraplantar formalin on two separate occasions. On one occasion, formalin was delivered to the hindpaw ipsilateral to the unilateral $\mathrm{Ce}$ treatment (muscimol or saline), and on the other occasion formalin was delivered to the contralateral hindpaw. Note the similar pattern of results obtained with the rating scale and flinch-frequency methods of nociceptive scoring. There were no significant differences in nociceptive scores under morphine between either group of unilateral Ce sham lesion rats and unilateral $\mathrm{Ce}$ lesion rats treated with contralateral formalin. In unilateral $\mathrm{Ce}$ lesion rats treated with ipsilateral formalin, however, morphine sulfate (4 $\mathrm{mg} / \mathrm{kg}$, s.c.) produced significantly less antinociception compared with all
Although a lesion approach was used in Experiments 1-4, a temporary inactivation procedure (injection of the $\mathrm{GABA}_{\mathrm{A}}$ agonist muscimol) was used in Experiment 5 to control for possible CNS reorganization in the days or weeks after the NMDA lesion. The results of Experiment 5 demonstrate that the pattern of results obtained in Experiments 1-4 is generalizable to another inactivation technique (Fig. 15).

\section{Hyperalgesia as a confound to the present results}

It could be argued that unilateral amygdala lesions result in ipsilateral hyperalgesia independent of a disruption in antinociceptive mechanisms, thereby accounting for effects observed in Experiments 1, 3, and 4 (Figs. 3, 11-13). Several factors count against this possibility, however. Baseline (i.e., systemic saline) nociceptive scores of unilateral Ce lesion rats treated with ipsilateral formalin were not different from those of any rats treated with systemic saline (e.g., Fig. 5). Similarly, intra-Ce injection of muscimol did not change baseline nociceptive scores (data not shown). These results suggest that $\mathrm{Ce}$ inactivation does not affect baseline behavioral responses to formalin injection and are consistent with the observation that behavioral responses to formalin are intact in decerebrate rats (Matthies and Franklin, 1992).

Although a hyperalgesic effect was not observed in relation to excitotoxin-induced lesions (Fig. 5) or muscimol inf usion, it could be argued that hyperalgesia was difficult to detect in the present experiments because the concentration of formalin used produces nociceptive scores that are already close to a behavioral "ceiling." Several lines of evidence suggest that this is not the case. A concentration of $1.0 \%$ formalin was chosen for intraplantar injection in Experiments 1-3 because it produces vigorous and easily quantifiable pain responses in rats. These responses are significantly lower in magnitude than those produced by higher doses of formalin (Coderre et al., 1993; Abbott et al., 1995), thereby making detection of hyperalgesia possible (Tjølsen et al., 1992). Because rats are capable of displaying higher nociceptive scores than the baseline scores obtained, it is unlikely that unilateral amygdalar inactivation produced a hyperalgesic effect in the present experiments.

\section{Dissociation of locomotor and antinociceptive effects of morphine}

The degree to which drug-induced reductions in nocifensive behaviors reflect specific effects on nociception or nonspecific motor effects remains a question of great concern in pain research (for a recent discussion of this issue, see Schomburg, 1997). This notion is of particular concern regarding pain assays that involve measuring the latency to perform a reflex withdrawal response (e.g., the tail flick test), because drug-induced motor complications may interfere with performance of the withdrawal response independent of changes in nociception. The formalin test may also be vulnerable to motor effects of drugs, because rats are free to move about in a test chamber during scoring of pain behaviors. Consequently, drugs that either decrease or increase locomotor activity levels (such as low doses of systemic morphine) may interfere with the expression of pain-related behaviors (Clarke and Franklin, 1992).

other groups. $B,{ }^{*} p<0.05 ;{ }^{* *} p<0.01$, Mann-Whitney $U$ test, compared with both groups of unilateral Ce sham lesion rats treated with systemic morphine; ${ }^{X} p 0.05$; ${ }^{X X} p<0.01$, Wilcoxon signed-rank test, compared with unilateral $\mathrm{Ce}$ lesion rats treated with systemic morphine plus contralateral formalin. 
To address this issue, horizontal locomotor activity was measured simultaneously with measurement of formalin pain behaviors (Sawynok et al., 1995) in the present experiments. The results indicate that $\mathrm{Ce}$ lesions can reduce the antinociceptive effect of morphine without reducing the stimulating effects of morphine on forward ambulation (Fig. 3, 11). Thus, two conclusions can be drawn: (1) as least some aspects of the locomotorstimulant and antinociceptive effects of morphine can be neuroanatomically dissociated; and (2) rats are capable of displaying high levels of pain-related behaviors in the formalin test despite high levels of forward ambulation. These observations suggest that drug-induced locomotor effects are unlikely to interfere with the expression of pain-related behaviors in the formalin test.

\section{Organization of amygdalar pain-modulating effects}

The mechanism by which amygdalar inactivation reduces morphine antinociception is unclear. Nevertheless, it is likely that pain-modulating circuits in the PAG, RVM, and spinal cord (see introductory remarks) are affected by amygdalar inactivation, because these circuits contribute to morphine antinociception in both the tail flick (Fields et al., 1991) and formalin (Abbott et al., 1996; Gilbert and Franklin, 1997; Manning and Franklin, 1998) tests under normal conditions. Thus, any discussion of the organization of neural circuitry underlying the present results necessitates discussion of these pain-modulating regions.

The present results are in agreement with earlier neuroanatomical tracing studies suggesting an ipsilateral topography of descending pain control circuits. Projections from the Ce to the ventrolateral PAG are primarily ipsilateral in nature (Hopkins and Holstege, 1978; Beitz, 1982; Rizvi et al., 1991; Shaikh et al., 1994). Similarly, projections from the PAG to the RVM target primarily ipsilateral portions of this region (Abols and Basbaum, 1981; Williams and Beitz, 1989; Van Bockstaele et al., 1991), and RVM neurons project primarily in the ipsilateral DLF to nociceptive neurons in dorsal horn laminae I, II, and IV-VI (Leichnetz et al., 1978; Basbaum and Fields, 1979; Watkins et al., 1980; Cho and Basbaum, 1989; Fields et al., 1995). This arrangement is depicted in Figure 16. Although the evidence cited above is consistent with the notion that pain-modulating neurons in the brain primarily influence nociceptive signals entering the ipsilateral dorsal horn, it should be pointed out that in each of these cases there is some innervation of contralateral portions of the target nucleus.

Because the PAG and RVM are both midline structures, it is difficult to examine the extent to which the PAG or RVM exerts ipsilateral versus contralateral control over spinal nociceptive responsiveness. The DLF, by contrast, is bilaterally represented in the spinal cord. Consequently, there have been attempts to determine the extent to which spinal nociceptive neurons are influenced by axons that course in the ipsilateral versus contralateral DLF. Early results obtained by Basbaum and colleagues were inconsistent in this regard. A unilateral lesion of the DLF was shown to reduce the inhibitory effect of electrical stimulation of the RVM (Fields et al., 1977) on nociceptive dorsal horn neurons located ipsilateral and caudal to the lesion. In contrast with the present results, however, a unilateral DLF lesion produced a reduction in simple behavioral indices of morphine- and stimulation-produced antinociception that was not consistently restricted to the ipsilateral hindpaw (Basbaum et al., 1977).

Surprisingly, several reports have suggested that the RVM exerts extensive bilateral control over nociceptive processing in the spinal cord. Jones and Gebhart (1987) showed that the inhi-

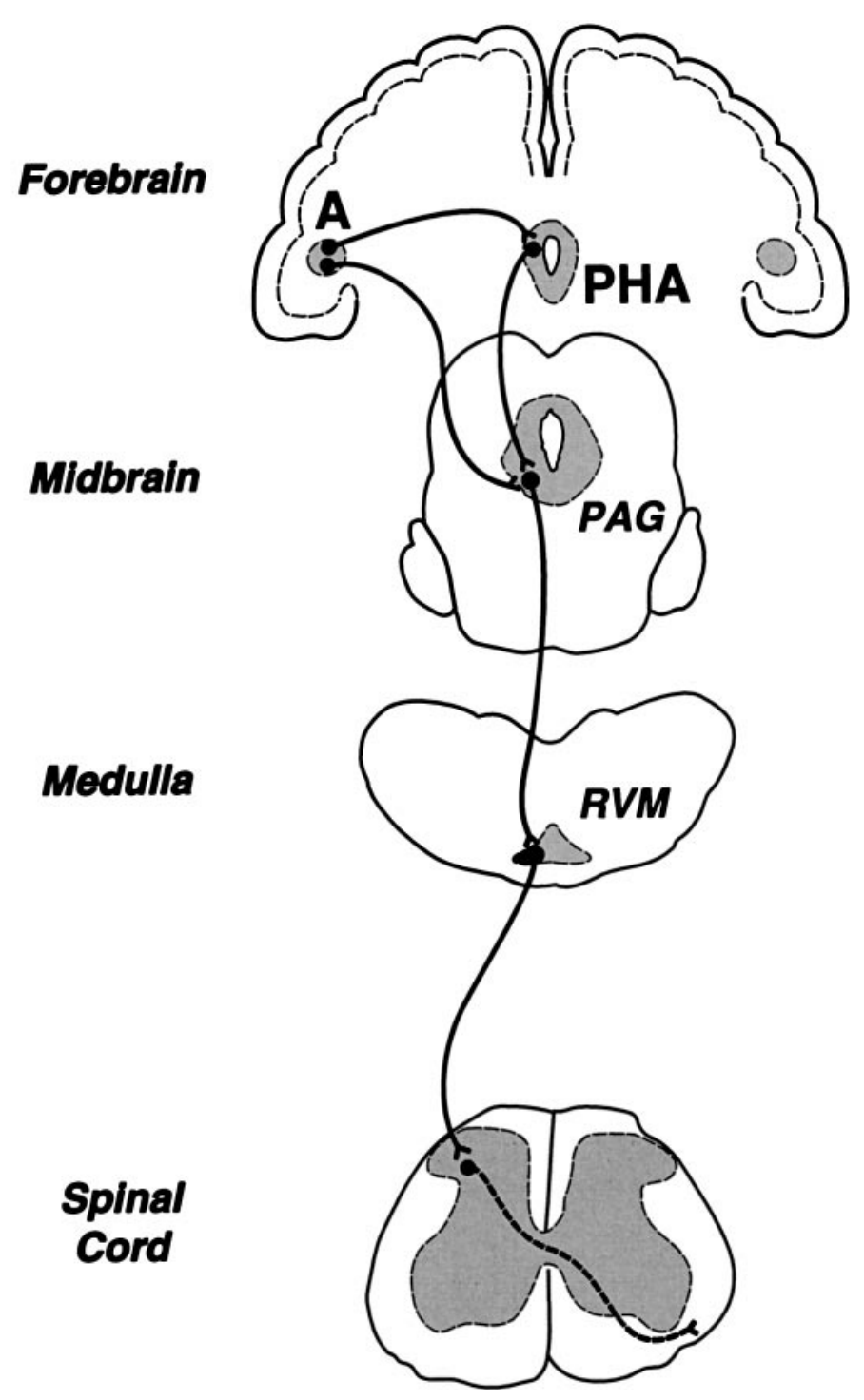

Figure 16. Simplified diagram of endogenous pain control circuitry in the rat brain. The diagram emphasizes centers that contribute to the antinociceptive effect of systemically administered morphine, including two novel forebrain contributors, the amygdala and the posterior hypothalamic area (PHA; Manning et al., 1994; Manning and Franklin, 1998). The amygdala is interconnected with the PAG and PHA (see references in Manning and Franklin, 1998). $A$, amygdala; $P A G$, midbrain periaqueductal gray matter; $R V M$, rostral ventromedial medulla.

bition of individual spinal nociceptive neurons produced by RVM stimulation is more effectively blocked by bilateral DLF lesions than a lesion produced ipsilateral to the spinal recording site. Even more surprisingly, Sandkühler et al. (1987) reported that a lesion contralateral, but not ipsilateral, to a spinal recording site reduced the inhibitory effects of RVM stimulation on spinal nociceptive neurons. Although these reports suggested a contribution of axons traveling in the contralateral DLF to control of spinal pain transmission neurons, this notion has not been investigated using behavioral antinociception as the measurement end point.

Pain, fear, antinociception, and the amygdala

It is clear from the present and previous (Manning and Mayer, $1995 a, b)$ results that the amygdala contributes strongly to the 
antinociceptive effect of systemically administered morphine. It is likely that amygdaloid circuitry contributing to "defensive behavior" (Graeff, 1994), including fear-induced antinociception (Helmstetter and Bellgowan, 1993; Mayer and Manning, 1995; Bellgowan and Helmstetter, 1996), overlaps at least partially with circuits contributing to morphine-induced antinociception (Manning and Mayer, 1995a,b). Because neural circuits in the PAG, RVM, and spinal cord (see introductory remarks) also contribute to morphine antinociception, the question remains of how these diverse CNS areas interact to produce the full antinociceptive effect of systemic morphine. Although the antinociceptive effect of direct opioid injection into the amygdala appears to be mediated in part through the PAG (Pavlovic et al., 1996; Helmstetter et al., 1998), it is unclear how connections between the Ce and ventrolateral PAG contribute to the integrity of descending pain control circuits.

\section{REFERENCES}

Abbott FV, Franklin KBJ, Westbrook RF (1995) The formalin test: scoring properties of the first and second phases of the pain response in rats. Pain 60:91-102.

Abbott FV, Hong Y, Franklin KBJ (1996) The effect of lesions of the dorsolateral funiculus on formalin pain and morphine analgesia: a dose-response analysis. Pain 65:17-23.

Abols IA, Basbaum AI (1981) Afferent connections of the rostral medulla of the cat: a neural substrate for midbrain-medullary interactions in the modulation of pain. J Comp Neurol 201:285-297.

Aggleton JP (1993) The contribution of the amygdala to normal and abnormal emotional states. Trends Neurosci 16:328-333.

Al-Rodhan N, Chipkin R, Yaksh TL (1990) The antinociceptive effects of SCH-32615, a neutral endopeptidase (enkephalinase) inhibitor, microinjected into the periaqueductal, ventral medulla and amygdala. Brain Res 520:123-130.

Basbaum AI, Fields HL (1979) The origin of descending pathways in the dorsolateral funiculus of the spinal cord of the cat and rat: further studies on the anatomy of pain modulation. J Comp Neurol 187:513-531.

Basbaum AI, Marley NJE, O'Keefe J, Clanton CH (1977) Reversal of morphine and stimulus-produced analgesia by subtotal spinal cord lesions. Pain 3:43-56.

Beitz AJ (1982) The organization of afferent projections to the midbrain periaqueductal gray of the rat. Neuroscience 7:133-159.

Bellgowan PS, Helmstetter FJ (1996) Neural systems for the expression of hypoalgesia during nonassociative fear. Behav Neurosci 110:727-736.

Cho HJ, Basbaum AI (1989) Arborization of single axons of the spinal dorsolateral funiculus to the contralateral superficial dorsal horn. Brain Res 477:344-349.

Clarke PBS, Franklin KBJ (1992) Infusions of 6-hydroxydopamine into the nucleus accumbens abolish the analgesic effect of amphetamine but not of morphine in the formalin test. Brain Res 580:106-110.

Coderre TJ, Fundytus ME, McKenna JE, Dalal S, Melzack R (1993) The formalin test: a validation of the weighted-scores method of behavioural pain rating. Pain 54:43-50.

Cohen SR, Abbott FV, Melzack R (1984) Unilateral analgesia produced by intraventricular morphine. Brain Res 303:277-287.

Fields HL, Basbaum AI, Clanton CH, Anderson SD (1977) Nucleus raphe magnus inhibition of spinal cord dorsal horn neurons. Brain Res 126:441-453.

Fields HL, Heinricher MM, Mason P (1991) Neurotransmitters in nociceptive modulatory circuits. Annu Rev Neurosci 14:219-245.

Fields HL, Malick A, Burstein R (1995) Dorsal horn projection targets of ON and OFF cells in the rostral ventromedial medulla. J Neurophysiol 74:1742-1759.

Gallagher M, Chiba AA (1996) The amygdala and emotion. Curr Opin Neurobiol 6:221-227.

Gilbert AK, Franklin KBJ (1997) Effects of direct administration of a $\mathrm{GABA}_{\mathrm{A}}$ agonist in the rostral ventromedial medulla on morphineinduced analgesia in rats. Soc Neurosci Abstr 23:156.

Graeff FG (1994) Neuroanatomy and neurotransmitter regulation of defensive behaviors and related emotions in mammals. Braz J Med Biol Res 27:811-829.
Hastings MH, Winn P, Dunnett SB (1985) Neurotoxic amino acid lesions of the lateral hypothalamus: a parametric comparison of the effects of ibotenate, $N$-methyl-D,L-aspartate and quisqualate in the rat. Brain Res 360:248-256.

Helmstetter FJ, Bellgowan PS (1993) Lesions of the amygdala block conditional hypoalgesia on the tail flick test. Brain Res 612:253-257.

Helmstetter FJ, Bellgowan PS, Tershner SA (1993) Inhibition of the tail flick reflex following microinjection of morphine into the amygdala. NeuroReport 4:471-474.

Helmstetter FJ, Bellgowan PSF, Poore LH (1995) Microinfusion of $m u$ but not delta or kappa opioid agonists into the basolateral amygdala results in inhibition of the tail flick reflex in pentobarbital-anesthetized rats. J Pharmacol Exp Ther 275:381-388.

Helmstetter FJ, Tershner ST, Poore LH, Bellgowan PSF (1998) Antinociception following opioid stimulation in the basolateral amygdala is expressed through the periaqueductal gray and rostral ventromedial medulla. Brain Res 779:104-118.

Hopkins DA, Holstege G (1978) Amygdaloid projections to the mesencephalon, pons and medulla oblongata in the cat. Exp Brain Res 32:529-547.

Jones SL, Gebhart GF (1987) Spinal pathways mediating tonic, coeruleospinal, and raphe-spinal descending inhibition in the rat. J Neurophysiol 58:138-159.

Kalivas PW, Gau BA, Nemeroff CB, Prange Jr AJ (1982) Antinociception after microinjection of neurotensin into the central amygdaloid nucleus of the rat. Brain Res 243:279-286.

Klamt JG, Prado WA (1991) Antinociception and behavioral changes induced by carbachol microinjected into identified sites of the rat brain. Brain Res 549:9-18.

Krupa DJ, Thompson JK, Thompson RF (1996) Localization of a memory trace in the mammalian brain. Science 110:219-227.

Leichnetz GR, Watkins L, Griffin G, Murfin R, Mayer DJ (1978) The projection from nucleus raphe magnus and other brainstem nuclei to the spinal cord in the rat: a study using the HRP blue-reaction. Neurosci Lett 8:119-124.

Manning BH, Franklin KBJ (1998) Morphine analgesia in the formalin test: reversal by microinjection of quaternary naloxone into the posterior hypothalamic area or periaqueductal gray. Behav Brain Res 92:97-102.

Manning BH, Mayer DJ (1995a) The central nucleus of the amygdala contributes to the production of morphine antinociception in the formalin test. Pain 63:141-152.

Manning BH, Mayer DJ (1995b) The central nucleus of the amygdala contributes to the production of morphine antinociception in the rat tail-flick test. J Neurosci 15:8199-8213.

Manning BH, Morgan MJ, Franklin KBJ (1994) Morphine analgesia in the formalin test: evidence for forebrain and midbrain sites of action. Neuroscience 63:289-294.

Martin JH (1991) Autoradiographic estimation of the extent of reversible inactivation produced by microinjection of lidocaine and muscimol in the rat. Neurosci Lett 127:160-164.

Matthies BK, Franklin KBJ (1992) Formalin pain is expressed in decerebrate rats but not attenuated by morphine. Pain 51:199-206.

Mayer DJ, Manning BH (1995) The role of opioid peptides in environmentally-induced analgesia. In: The pharmacology of opioid peptides (Tseng LF ed), pp 345-395. Chur, Switzerland: Harwood.

Oliveira MA, Prado WA (1994) Antinociception and behavioral manifestations induced by intracerebroventricular or intra-amygdaloid administration of cholinergic agonists in the rat. Pain 57:383-391.

Pavlovic ZW, Bodnar RJ (1998) Opioid supraspinal synergy between the amygdala and periaqueductal gray in rats. Brain Res 779:158-169.

Pavlovic ZW, Cooper ML, Bodnar RJ (1996) Opioid antagonists in the periaqueductal gray inhibit morphine and $\beta$-endorphin analgesia elicited from the amygdala of rats. Brain Res 741:13-26.

Paxinos G, Watson C (1986) The rat brain in stereotaxic coordinates. New York: Academic.

Proudfit HK, Yeomans DC (1995) The modulation of nociception by enkephalin-containing neurons in the brainstem. In: The pharmacology of opioid peptides (Tseng LF ed), pp 197-217. Chur, Switzerland: Harwood.

Rizvi TA, Ennis M, Behbehani MM, Shipley MT (1991) Connections between the central nucleus of the amygdala and the midbrain periaqueductal gray: topography and reciprocity. J Comp Neurol 303:121-131.

Robinson FR, Straube A, Fuchs AF (1993) Role of the caudal fastigial 
nucleus in saccade generation. II. Effects of muscimol inactivation. J Neurophysiol 94:418-428.

Rodgers RJ (1977) Elevation of aversive threshold in rats by intraamygdaloid injection of morphine sulphate. Pharmacol Biochem Behav 6:385-390.

Rosland JH, Tjølsen A, Maehle B, Hole K (1990) The formalin test in mice: effect of formalin concentration. Pain 42:235-242.

Ryan SM, Watkins LR, Mayer DJ, Maier SF (1985) Spinal pain suppression mechanisms may differ for phasic and tonic pain. Brain Res 334:173-175.

Sandkühler J, Maisch B, Zimmermann M (1987) Raphe magnusinduced descending inhibition of spinal nociceptive neurons is mediated through contralateral spinal pathways in the cat. Neurosci Lett [erratum (1987) 83:212] 76:168-172.

Sawynok J, Reid AR, Doak GJ (1995) Caffeine antinociception in the rat hot-plate and formalin tests and locomotor stimulation: involvement of noradrenergic mechanisms. Pain 61:203-213.

Schomburg ED (1997) Restrictions on the interpretation of spinal reflex modulation in pain and analgesia research. Pain Forum 6:101-109.

Segal DS, Kuczenski R (1992) Repeated cocaine administration induces behavioral sensitization and corresponding decreased extracellular dopamine responses in caudate and accumbens. Brain Res 577:351-355.

Shaikh MB, Schubert K, Siegel A (1994) Basal amygdaloid facilitation of midbrain periaqueductal gray elicited defensive rage behavior in the cat is mediated through NMDA receptors. Brain Res 635:187-195.

Tallarida RJ, Murray RB (1987) Manual of pharmacologic calculations with computer programs, Ed 2. New York: Springer.

Tjølsen A, Berge O-G, Hunskaar S, Rosland JH, Hole K (1992) The formalin test: an evaluation of the method. Pain 51:5-17.
Van Bockstaele EJ, Aston-Jones G, Pieribone VA, Ennis M, Shipley MT (1991) Subregions of the periaqueductal gray topographically innervate the rostral ventral medulla in the rat. J Comp Neurol 309:305-327.

Watkins LR, Griffin G, Leichnetz GR, Mayer DJ (1980) The somatotopic organization of the nucleus raphe magnus and surrounding brain stem structures as revealed by HRP slow-release gels. Brain Res 181:1-15.

Wheeler-Aceto H, Cowan A (1991) Standardization of the rat paw formalin test for the evaluation of analgesics. Psychopharmacology 104:35-44.

Williams FG, Beitz AJ (1989) A quantitative ultrastructural analysis of neurotensin-like immunoreactive terminals in the midbrain periaqueductal gray: analysis of their possible relationship to periaqueductal gray-raphe magnus projection neurons. Neuroscience 29:121-134.

Winn P, Clark A, Hastings M, Clark J, Latimer M, Rugg E, Brownlee B (1990) Excitotoxic lesions of the lateral hypothalamus made by $N$-methyl-D-aspartate in the rat: behavioural, histological and biochemical analyses. Exp Brain Res 82:628-636.

Winn P, Stone TW, Latimer M, Hastings MH, Clark AJM (1991) A comparison of excitotoxic lesions of the basal forebrain by kainate, quinolinate, ibotenate, $N$-methyl-D-aspartate or quisqualate, and the effects on toxicity of 2-amino-5-phosphonovaleric acid and kynurenic acid in the rat. Br J Pharmacol 102:904-908.

Wise RA, Gingras MA, Amit Z (1996) Influence of novel and habituated testing conditions on cocaine sensitization. Eur J Pharmacol 307:15-19. 